University of Nebraska - Lincoln

DigitalCommons@University of Nebraska - Lincoln

Response of Nebraska Sand Hills Natural Vegetation to Drought, Fire, Grazing, and Plant Functional Type Shifts as Simulated by the Century Model

\author{
Jennifer Mangan \\ Digital Library for Earth System Education, University Corporation for Atmospheric Research \\ Jonathan T. Overpeck \\ University of Arizona, Tucson, Arizona \\ Robert S. Webb \\ University of Colorado, Boulder, and NOAA Climate Diagnostics Center, 325 N. Broadway, Boulder, CO \\ Carol Wessman \\ University of Colorado, Boulder, CO \\ Alexander Goetz \\ University of Colorado, Boulder, $\mathrm{CO}$
}

Follow this and additional works at: https://digitalcommons.unl.edu/natrespapers

Part of the Natural Resources and Conservation Commons

Mangan, Jennifer; Overpeck, Jonathan T.; Webb, Robert S.; Wessman, Carol; and Goetz, Alexander, "Response of Nebraska Sand Hills Natural Vegetation to Drought, Fire, Grazing, and Plant Functional Type Shifts as Simulated by the Century Model" (2004). Papers in Natural Resources. 143.

https://digitalcommons.unl.edu/natrespapers/143

This Article is brought to you for free and open access by the Natural Resources, School of at DigitalCommons@University of Nebraska - Lincoln. It has been accepted for inclusion in Papers in Natural Resources by an authorized administrator of DigitalCommons@University of Nebraska - Lincoln. 


\title{
RESPONSE OF NEBRASKA SAND HILLS NATURAL VEGETATION TO DROUGHT, FIRE, GRAZING, AND PLANT FUNCTIONAL TYPE SHIFTS AS SIMULATED BY THE CENTURY MODEL
}

\author{
JENNIFER M. MANGAN ${ }^{1}$, JONATHAN T. OVERPECK ${ }^{2}$, ROBERT S. WEBB ${ }^{3}$, \\ CAROL WESSMAN $^{4}$ and ALEXANDER F. H. GOETZ ${ }^{5}$ \\ ${ }^{1}$ Digital Library for Earth System Education, University Corporation for Atmospheric Research, \\ P.O. Box 3000, Boulder, CO 80307-3000, U.S.A. \\ E-mail:mangan@email.arizona.edu \\ ${ }^{2}$ Institute for the Study of Planet Earth and Department of Geosciences, University of Arizona, \\ Tucson, Arizona 85721, U.S.A. \\ E-mail: jto@u.arizona.edu \\ ${ }^{3}$ Department of Geological Sciences and INSTAAR, University of Colorado, Boulder, and NOAA \\ Climate Diagnostics Center, 325 N. Broadway, Boulder, CO 80305, U.S.A. \\ E-mail: Robert.S.Webb@noaa.gov \\ ${ }^{4}$ Department of Evolutionary, Population, and Organismic Biology and Cooperative Institute for \\ Research in Environmental Science, CB 216, University of Colorado, Boulder, CO 80309, U.S.A. \\ E-mail: wessman@cses.colorado.edu \\ ${ }^{5}$ Department of Geological Sciences and Center for the Study of Earth from Space, Cooperative \\ Institute for Research in Environmental Science, CB 216, University of Colorado, \\ Boulder, CO 80309, U.S.A. \\ E-mail: goetz@cses.colorado.edu
}

\begin{abstract}
The Nebraska Sand Hills exist in a semi-arid climatic environment and the land surface is grassland growing on sandy soils. These soils have been periodically active throughout the Holocene, but are currently stabilized by the vegetation. However, a shift in climate could cause grassland death and eventual sand dune remobilization. Our studies used the CENTURY nutrient cycling and ecosystem model to investigate the impacts of drought, plant functional type, fire, grazing, and erosion on Nebraska Sand Hills vegetation and dune stability. Fire and grazing alone had little impact on the vegetation, but when combined with mild drought, biomass decreased. Overall biomass increased if one plant functional type was allowed to dominate the ecosystem. Addition of as little as $1 \mathrm{~mm}$ of erosion per year under current climate conditions decreases vegetation as much as a drought 20 percent drier than the worst of the 1930s drought years in Nebraska.
\end{abstract}

\section{Introduction}

Understanding the effects of drought on vegetation is important for assessing soil mobilization potential. The 1930s are the driest years in the 150 -year meteorological record for Nebraska (Earth Info, 2000). However, sand was not remobilized even though soils were exposed in some areas due to vegetation death (Weaver and Albertson, 1940; Weaver, 1943). The magnitude of drought that characterized the 1930s was enough to disturb fine-grained farm soils and the crops growing on 
them, but it was not long or severe enough to activate undisturbed and naturally vegetated coarse sand (Muhs, 1998).

Droughts of both greater intensity and duration than those of the 20th century caused death of vegetation and subsequent dune activity in the mid- to late Holocene (Holliday, 1989; Stokes and Swinehart, 1997). Episodes of sand mobilization have occurred in the Nebraska Sand Hills multiple times during this period (Ahlbrandt et al., 1993; Muhs et al., 1997; Stokes and Swinehart, 1997). The Sand Hills today are made up of one hundred thousand square kilometers of largely stabilized sand dunes and sand sheets covered by thin soil horizons. The Sand Hills were active as recently as the mid-1800s (Muhs and Holliday, 1995).

Sufficient sediment is currently available for transport and winds are of high enough velocity to cause sand dune mobility on the High Plains (Muhs and Maat, 1993). However, the sand dunes and sand sheets of the Nebraska Sand Hills are stable because of vegetation cover (Muhs and Maat, 1993). During the mid- to late Holocene dune activation episodes, adequate stabilizing vegetation cover was most likely absent (Muhs and Maat, 1993). If the current stabilizing vegetation were to disappear in the future, sand could again mobilize at the same scale as in the midto late Holocene.

Paleoclimatic data suggest that droughts of much greater length and magnitude than the drought of the 1930s have happened in the past and could occur again in the future (Woodhouse and Overpeck, 1999). Lake-level data from Nebraska (Qin et al., 1998) indicate regionally drier conditions at about 6 ka. Stratigraphic studies in eastern Colorado document regional, episodic eolian deposition around $6 \mathrm{ka}$ (Jorgenson, 1992). Carbon dating of buried organic matter and thermoluminescence dating of sands in eastern Colorado and Nebraska also confirm the existence of mid-Holocene dune mobility at $6 \mathrm{ka}$ (Forman et al., 1995). Model simulations (Kutzbach et al., 1998; Bartlein et al., 1998) suggest that at 6 ka the U.S. High Plains were 1 to $2{ }^{\circ} \mathrm{C}$ warmer than today during the summer growing season months of June, July, and August. Warmer temperatures may have led to increased evapotranspiration and less available moisture (Rind et al., 1990). Climate model experiments (Kutzbach et al., 1998; Bartlein et al., 1998) also suggest that less moisture was available 6 thousand years ago than at present; these results are consistent with lake-level data (Qin et al., 1998).

This study focuses on the Nebraska Sand Hills, a currently stable region on the High Plains with dunes of late Quaternary origin. We postulate that increased growing season aridity resulting in greater moisture stress would result in the death of soil-stabilizing vegetation in the mid- and late Holocene. The sand stability during the 1930s drought may have been due to the continued presence of underground plant rooting systems, either dead or dormant, throughout the drought. The roots would still serve as a binding agent for the soil and prevent it from blowing away. Weaver (1954) has noted that vegetation roots on the High Plains may lie dormant for years, even when aboveground biomass is absent. Thus, it is important to consider both aboveground biomass (shoots) and belowground biomass (roots 
and soil microbes) when assessing vegetation in relation to sand dune stability. Temperature and moisture availability are other factors which contribute directly to dune stability because an area with sandy soil will drain more easily and hence retain less moisture than a less sandy region.

The Nebraska Sand Hills are characterized by a mixed grassland or prairie (Weaver, 1956). A mix of $\mathrm{C}_{3}$ (cool season) and $\mathrm{C}_{4}$ (warm season) photosynthetic pathway plants exists in the Sand Hills (Paruelo and Lauenroth, 1996). In the event of a drought, however, the balance between these two plant functional types could shift to favor one or the other. Seasonality of precipitation is one factor that can influence the predominance of $C_{3}$ or $C_{4}$ vegetation (Weaver, 1956), with $C_{3}$ species favoring moist spring seasons and $\mathrm{C}_{4}$ species requiring summer moisture. Temperature is another factor. Increasing spring minimum temperatures correlates with decreased $C_{4}$ productivity and benefits $C_{3}$ species since $C_{3}$ plants are growing most rapidly during spring (Alward et al., 1999). Flourishing cool season species could effectively reduce the amount of resources available to warm season species that begin their growth peaks later in the year.

The goal of this study is to determine the range of climate conditions that might lead to widespread mobilization of High Plains eolian landforms because of death of vegetation cover on the dunes. We used the CENTURY ecosystem model to simulate vegetation response to a variety of climatic scenarios (Parton et al.; 1987, 1988). Initially, we assessed aboveground and belowground vegetation response to observed twentieth century climate for a 50 percent $C_{3}, 50$ percent $C_{4}$ grassland. To complement these model studies, we also simulated soil nitrogen dynamics, since nitrogen plays an integral role in terrestrial ecosystem productivity (Reich et al., 2001; Knops et al., 2001; Symstad and Tilman, 2001). We also simulated vegetation dynamics under conditions of prolonged mild drought by rescaling 1935-1989 average precipitation to 1934 drought values. We then observed the effects of up to sixty percent less precipitation than 1934 applied over a 56-year period. Further, we simulated fire and grazing regimes to determine the impact of each on plant shoots and rooting systems. Lastly, the community structure of the grassland was altered and the CENTURY mode was run to predict biomass amounts and soil nitrogen dynamics for species-relative abundances ranging from 100 percent $C_{3}$ species to 100 percent $\mathrm{C}_{4}$ species. Knowing which environmental variables have the greatest impacts on an ecosystem can improve predictions of vegetation responses under a wide range of drought scenarios. A thorough understanding of the environmental factors that affect vegetation communities could also lead to more informed management practices in the face of climate variability, particularly since we likely face the possibility of climatic extremes (e.g., drought) far in excess of those seen in the 20th century (Overpeck, 1996).

Simulations of aboveground and belowground live carbon are important for assessing the physical presence of vegetation in a region as it responds to various climatic and environmental conditions. Less visible but equally important are the parameters soil carbon and soil nitrogen. Total soil carbon measures how much 
nutrient carbon is available for plants to uptake, and it is also a measure of how much carbon remains in the soil after root and shoot death. Nitrogen is also a critical consideration because productivity in terrestrial ecosystems is most often limited by N (Reich et al., 2001; Knops et al., 2001; Symstad and Tilman, 2001).

\section{Methods and Data}

The CENTURY ecosystem model was used to simulate vegetation and soil nitrogen response to drought. CENTURY was developed to predict carbon and nutrient cycling in semi-arid temperate grasslands, such as those which naturally exist on the U.S. High Plains (Parton et al., 1987, 1988, 1993, 1994; Bolker et al., 1998). The model predicts aboveground and belowground plant biomass, as well as soil nutrient dynamics, in response to the environmental constraints of temperature, moisture availability, and soil texture (Parton et al., 1987, 1988, 1993, 1994; Bolker et al., 1998) and has had a proven success rate with semi-arid grasslands, predicting carbon abundances to within 25 percent of what has been observed in the field (Parton et al., 1993). In addition to the basic vegetation-regulating parameters of soil texture, water availability, and temperature, other environmental factors, e.g. fire and grazing, may influence grassland vegetation. The goal with these CENTURY model studies is to assess possible vegetation response to drought for a variety of scenarios.

A primary goal of our modeling efforts is to constrain the range of climate conditions that might lead to widespread mobilization of High Plains eolian land forms because of removal of vegetation cover from the dunes. The CENTURY ecosystem model was used to investigate how aboveground and belowground biomass are influenced by climate (i.e., precipitation and temperature) and thus how climate-induced changes in biomass would impact sand dune stability in the Nebraska Sand Hills. CENTURY is a point-specific nutrient cycling model that was developed specifically for High Plains grasslands and is therefore ideally suited for the modeling needs of this study (Parton et al., 1987, 1988, 1993, 1994; Schimel et al., 1990; Bolker et al., 1998). Input variables include minimum and maximum monthly temperatures, monthly precipitation, soil texture, and initial vegetation community composition.

The study region is Halsey, NE, in the central portion of the Nebraska Sand Hills at $41.90^{\circ} \mathrm{N}$ latitude, $100.30^{\circ} \mathrm{W}$ longitude (Figure 1). Mean annual precipitation in Halsey is between 500 and 550 millimeters per year, based on yearly averages from 1970-1989, and most of the rainfall occurs from April through June. Halsey monthly climate data from 1904-1989 was the climate input for the CENTURY model simulations, but the model was spun up using stochastic climate for 2000 years prior to generating output. The lengthy spin-up time allows all the carbon and nitrogen pools in the model to fill and thus be available for interaction during the actual experiments themselves. A soil texture of 92 percent sand, 4 percent silt, and 
High Plains Sandy Soils Distribution

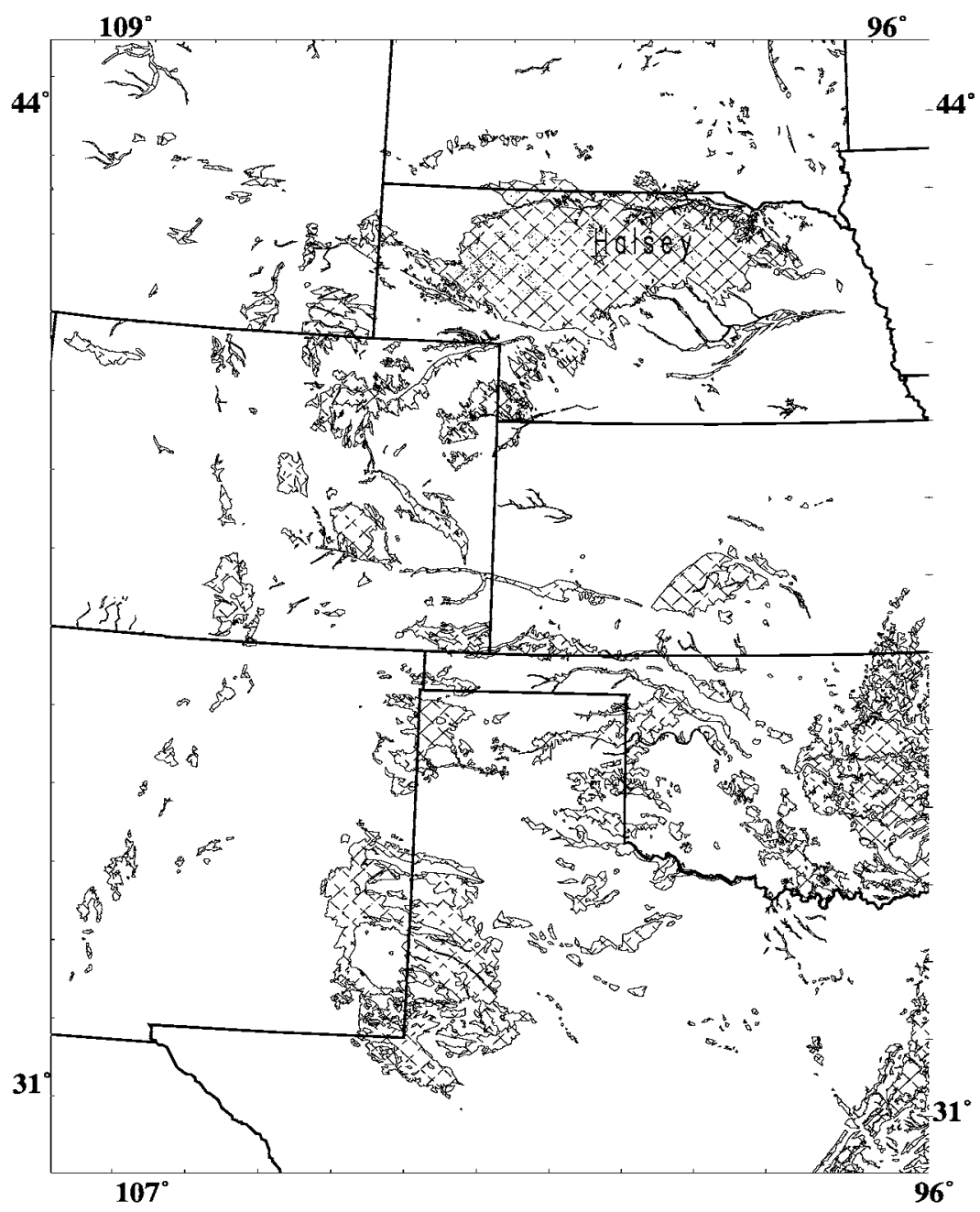

Figure 1. Map of the U.S. High Plains. Crosshatching indicates sandy soils and the location of the climate input data site, Halsey, NE, is shown.

4 percent clay, representative of the soil texture for most of the Sand Hills (State Soil Geographic [STATSGO] survey database U.S. Department of Agriculture, 1994) was assigned for all model runs. The initial vegetation community in the model run determines the amounts of plant lignin and metabolic carbon available for decomposition.

The CENTURY model was run for control, drought, fire and grazing simulations using the 50 percent warm-grass $\left(\mathrm{C}_{4}\right.$ photosynthetic pathway), 50 percent cool-grass $\left(\mathrm{C}_{3}\right.$ photosynthetic pathway) mixed-grassland vegetation type (Table $\left.\mathrm{I}\right)$. 
Table I

Summary and description of input for all CENTURY model experiments

\begin{tabular}{|c|c|c|c|c|c|}
\hline Model run description & Climate input & Fire regime & Grazing regime & Erosion routine & $\mathrm{C}_{3} / \mathrm{C}_{4}$ ratio \\
\hline Control & $\begin{array}{l}\text { Observed NCDC modern climate } \\
\text { data 1904-1989 }\end{array}$ & none & none & none & $50 \% / 50 \%$ \\
\hline Extended 1934 & $\begin{array}{l}\text { Observed NCDC modern climate } \\
\text { data 1904-1934, 1935-1989 } \\
\text { mean climate rescaled to } 1934 \\
\text { values } 1935-1989\end{array}$ & none & none & none & $50 \% / 50 \%$ \\
\hline $\begin{array}{l}1934 \text { precipitation minus } \\
10 \%\end{array}$ & $\begin{array}{l}\text { Observed NCDC modern climate } \\
\text { data 1904-1934, 1934 } \\
\text { precipitation decreased } 10 \% \\
\text { 1935-1989 }\end{array}$ & none & none & none & $50 \% / 50 \%$ \\
\hline $\begin{array}{l}1934 \text { precipitation minus } \\
20 \%\end{array}$ & $\begin{array}{l}\text { Observed NCDC modern climate } \\
\text { data 1904-1934, } 1934 \\
\text { precipitation decreased } 20 \% \\
1935-1989\end{array}$ & none & none & none & $50 \% / 50 \%$ \\
\hline $\begin{array}{l}1934 \text { precipitation minus } \\
30 \%\end{array}$ & $\begin{array}{l}\text { Observed NCDC modern climate } \\
\text { data 1904-1934, } 1934 \\
\text { precipitation decreased } 30 \% \\
1935-1989\end{array}$ & none & none & none & $50 \% / 50 \%$ \\
\hline $\begin{array}{l}1934 \text { precipitation minus } \\
40 \%\end{array}$ & $\begin{array}{l}\text { Observed NCDC modern climate } \\
\text { data 1904-1934, } 1934 \\
\text { precipitation decreased } 40 \% \\
1935-1989\end{array}$ & none & none & none & $50 \% / 50 \%$ \\
\hline $\begin{array}{l}1934 \text { precipitation minus } \\
50 \%\end{array}$ & $\begin{array}{l}\text { Observed NCDC modern climate } \\
\text { data 1904-1934, } 1934 \\
\text { precipitation decreased } 50 \% \\
1935-1989\end{array}$ & none & none & none & $50 \% / 50 \%$ \\
\hline $\begin{array}{l}1934 \text { precipitation minus } \\
60 \%\end{array}$ & $\begin{array}{l}\text { Observed NCDC modern climate } \\
\text { data 1904-1934, } 1934 \\
\text { precipitation decreased } 60 \% \\
1935-1989\end{array}$ & none & none & none & $50 \% / 50 \%$ \\
\hline Fire & $\begin{array}{l}\text { Observed NCDC modern climate } \\
\text { data 1904-1934, 1935-1989 } \\
\text { mean climate rescaled to } 1934 \\
\text { values } 1935-1989\end{array}$ & $\begin{array}{l}\text { 'cold' fire every } 3 \text { rd } \\
\text { year }-60 \% \text { vegetation } \\
\text { removal }\end{array}$ & & none & $50 \% / 50 \%$ \\
\hline Annual grazing & $\begin{array}{l}\text { Observed NCDC modern climate } \\
\text { data 1904-1934, 1935-1989 } \\
\text { mean climate rescaled to } 1934 \\
\text { values } 1935-1989\end{array}$ & none & $\begin{array}{l}\text { May-September low- } \\
\text { intensity grazing } \\
\text { with linear effect on } \\
\text { production }\end{array}$ & none & $50 \% / 50 \%$ \\
\hline $75 \% \mathrm{C} 3$ & $\begin{array}{l}\text { Observed NCDC modern climate } \\
\text { data 1904-1934, 1935-1989 } \\
\text { mean climate rescaled to } 1934 \\
\text { values } 1935-1989\end{array}$ & none & none & none & $\begin{array}{l}50 \% / 50 \% \\
1904-1934, \\
75 \% / 75 \% \\
1935-1989\end{array}$ \\
\hline $100 \% \mathrm{C} 3$ & $\begin{array}{l}\text { Observed NCDC modern climate } \\
\text { data 1904-1934, 1935-1989 } \\
\text { mean climate rescaled to } 1934 \\
\text { values } 1935-1989\end{array}$ & none & none & none & $\begin{array}{l}50 \% / 50 \% \\
1904-1934, \\
100 \% / 0 \% \\
1935-1989\end{array}$ \\
\hline $75 \% \mathrm{C} 4$ & $\begin{array}{l}\text { Observed NCDC modern climate } \\
\text { data 1904-1934, 1935-1989 } \\
\text { mean climate rescaled to } 1934 \\
\text { values } 1935-1989\end{array}$ & none & none & none & $\begin{array}{l}50 \% / 50 \% \\
1904-1934, \\
25 \% / 75 \% \\
1935-1989\end{array}$ \\
\hline $100 \% \mathrm{C} 4$ & $\begin{array}{l}\text { Observed NCDC modern climate } \\
\text { data } 1904-1934,1935-1989 \\
\text { mean climate rescaled to } 1934 \\
\text { values } 1935-1989\end{array}$ & none & none & none & $\begin{array}{l}50 \% / 50 \% \\
1904-1934, \\
0 \% / 100 \% \\
1935-1989\end{array}$ \\
\hline
\end{tabular}


Table I

(Continued)

\begin{tabular}{|c|c|c|c|c|c|}
\hline Model run description & Climate input & Fire regime & Grazing regime & Erosion routine & $\mathrm{C}_{3} / \mathrm{C}_{4}$ ratio \\
\hline Erosion $1 \mathrm{~mm}$ & $\begin{array}{l}\text { Observed NCDC modern climate } \\
\text { data 1904-1934, 1935-1989 } \\
\text { mean climate rescaled to } 1934 \\
\text { values 1935-1989 }\end{array}$ & none & none & $\begin{array}{l}1 \mathrm{~mm} \text { monthly, } \\
\text { January through } \\
\text { April, 1935-1989 }\end{array}$ & $50 \% / 50 \%$ \\
\hline Erosion $0.75 \mathrm{~mm}$ & $\begin{array}{l}\text { Observed NCDC modern climate } \\
\text { data } 1904-1934,1935-1989 \\
\text { mean climate rescaled to } 1934 \\
\text { values } 1935-1989\end{array}$ & none & none & $\begin{array}{l}0.75 \mathrm{~mm} \text { monthly, } \\
\text { January through } \\
\text { April, 1935-1989 }\end{array}$ & $50 \% / 50 \%$ \\
\hline Erosion $0.5 \mathrm{~mm}$ & $\begin{array}{l}\text { Observed NCDC modern climate } \\
\text { data 1904-1934, 1935-1989 } \\
\text { mean climate rescaled to } 1934 \\
\text { values } 1935-1989\end{array}$ & none & none & $\begin{array}{l}0.5 \mathrm{~mm} \text { monthly, } \\
\text { January through } \\
\text { April, 1935-1989 }\end{array}$ & $50 \% / 50 \%$ \\
\hline Erosion $0.25 \mathrm{~mm}$ & $\begin{array}{l}\text { Observed NCDC modern climate } \\
\text { data 1904-1934, 1935-1989 } \\
\text { mean climate rescaled to } 1934 \\
\text { values } 1935-1989\end{array}$ & none & none & $\begin{array}{l}0.25 \mathrm{~mm} \text { monthly, } \\
\text { January through } \\
\text { April, 1935-1989 }\end{array}$ & $50 \% / 50 \%$ \\
\hline
\end{tabular}

A mixed grassland type typifies much of the Sand Hills whereas other portions range up to entirely $\mathrm{C}_{4}$ grassland (Paruelo and Lauenroth, 1996). The CENTURY model specifies that belowground biomass is present in greater abundance than aboveground biomass in a mixed grassland. Often plants in drought-susceptible regions have developed extensive root systems that extend deep into the soil or radiate outward to take advantage of as much available water as possible (Weaver and Albertson, 1954; Weaver, 1956).

The CENTURY control run for the years 1904 to 1989 used observed modern climate data for Halsey, NE and was designed to simulate natural variations in biomass production year-to-year. Another purpose of the control run was to detect vegetation changes resulting from the 1930s drought stress; 1934 was the driest year in the Halsey climate record. To simulate the potential effects not only of a long drought of 1930s magnitude, but also of more severe extended droughts, a series of 6 additional CENTURY experiments was carried out to identify the precipitation threshold at which vegetation would be critically low or absent. These 6 experiments rescaled the 1934-1989 monthly precipitation values to have means equal to the 1934 precipitation values decreased in 10 percent increments up 60 percent. We then ran the model with observed values from 1904-1934 and each of the reduced precipitation scenarios from 1935-1989. Note that the paleoclimatic record of drought over millennia (Woodhouse and Overpeck, 1999) suggests that 1934 conditions probably constituted only 'mild drought' in the context of observed past drought variability.

The control simulation did not account for the effects of grazing, therefore another CENTURY model simulation was run with annual low-intensity grazing from May through September and 1934 'mild drought' mean precipitation values 
superimposed with 1935-1989 natural variability. Including grazing effects in paleoclimatic simulations is important because bison and other large grazing animals were present for thousands of years prior to the 20th century (Loope, 1986). Some plant species increase their production in response to grazing while others decrease their production (Stubbendieck et al., 1985). Herbivores also serve the important function of returning nutrients in the form of metabolic waste to the soil. A moderate grazing regime in CENTURY thus likely simulates the natural conditions on High Plains rangeland.

The control CENTURY run did not account for fire on the High Plains. However, grassland fire events naturally occur approximately every 3 to 5 years on the High Plains (Parton et al., 1993). Fire can influence the nitrogen budgets in grassland ecosystems (Hobbs et al., 1991), and can alter nutrient cycling processes (Ojima et al., 1994). To evaluate the impact of a change in summertime fire regime on biomass, a CENTURY simulation was run with a 'cold' fire every three years under the rescaled 1934 mild drought conditions. Under modern climate conditions, a cold fire will remove 60 percent of the available aboveground biomass in the model (Parton et al., 1987, 1988).

The choice of plant functional types also regulates CENTURY biomass production. The Nebraska Sand Hills currently has an equal mix of $\mathrm{C}_{3}$ and $\mathrm{C}_{4}$ plants growing in some regions and 75 percent $\mathrm{C}_{4}$ plants in other regions (Paruelo and Lauenroth, 1996). In the event of a significant drought or climate shift, either of these plant types could increase in abundance relative to the other. To test the dynamics of plant functional types during a drought, we ran a set of CENTURY experiments with a range of $\mathrm{C}_{3} / \mathrm{C}_{4}$ ratios combined with climate input that had 1935-1989 precipitation values re-scaled to the 1934 monthly means. We ran the model with $\mathrm{C}_{3}$ plant abundances of 25 percent, 50 percent, 75 percent, and 100 percent. These model runs were designed to predict overall aboveground and belowground biomass production in the entire ecosystem when different ratios of $\mathrm{C}_{3}$ and $\mathrm{C}_{4}$ plants are present. For an assessment of dune stability as a function of vegetation cover, it is important to know overall plant abundance regardless of species or functional type (Valdez, 1990).

All of the model runs above describe not only the CENTURY experiments we used to assess aboveground and belowground live carbon, but also the basic framework for model simulations that assess other environmental impacts and model output. For the control, successive drought severity increase, grazing, fire, and plant functional type shift CENTURY simulations, we also looked at the dynamics of soil nitrogen. Knowing how soil nitrogen responds to different environmental situations can afford clues to the dynamics of the vegetation community, since plants and nitrogen are interdependent.

In addition, for all of the above-mentioned CENTURY runs, we simulated the effects of erosion, starting in 1934. Erosion is a widely-documented effect of the Dust Bowl drought (Weaver and Albertson, 1940; Weaver, 1954), and its inclusion in these model simulations should provide a more accurate picture of vegetation 
dynamics during a drought. We eroded the soil $0.25 \mathrm{~mm}, 0.50 \mathrm{~mm}, 0.75 \mathrm{~mm}$, and $1.0 \mathrm{~mm}$ monthly from January through April, beginning in the initial drought year, 1934. If erosion of $4 \mathrm{~mm}$ monthly, the largest amount simulated, were to continue in the face of severe drought, it would yield a total erosion amount of about 0.4 meters per Century, well below the up to 6 meters observed in the dune fields of Nebraska (S. Forman, personal communication.) Erosion was prescribed from January through April because these are the four months immediately preceding the start of the growing season, and the soil is most likely to be bare and therefore most susceptible to mobilization.

The erosion routine in CENTURY does not physically impact vegetation, nor does it cause surface removal of the litter layer by wind. Erosion does, however, cause the loss of carbon, nitrogen, and other nutrients in the soil. The lost nutrients are removed from surface soil organic matter pools and belowground structural and metabolic pools. Century 4 erodes soil and nutrients from only the top 20 centimeters of soil and replaces the nutrients and organic matter with nutrients and organic matter obtained from the lower soil horizon. Input from the next soil horizon uses an equivalent depth of soil to that eroded. Nutrients are leached from litter and dead plant material by another subroutine, and these nutrients become available for removal or cycling within the soil layers when erosion occurs in the model.

\section{Statistical Testing}

A primary goal of adding four different erosion routines to all CENTURY simulations was to gauge the impact of erosion on ecosystems stressed by various levels of drought, thereby providing a measure of how erosion can magnify the effects of drought alone. Therefore it was critical to find an accurate method for comparing the results of all CENTURY runs under all five erosion conditions $(0,0.25,0.5$, $0.75,1.0 \mathrm{~mm}$ monthly, January through April) and all eight climate situations (observed, 1934 precipitation, 10-60 percent less than 1934 precipitation). Two statistical tests were evaluated.

Initially, we evaluated the differences between all CENTURY model runs using the Kolmogorov-Smirnov statistical test in the SPSS statistics program package. The Kolmogorov-Smirnov test is non-parametric and computes the maximum absolute difference in the cumulative probability curves from the data, which are scaled to be between 0 and 1.0, and determines the largest difference between corresponding points on the resulting histogram (Causton and Venus, 1981; Shaw and Wheeler, 1985). Therefore the $\mathrm{K}-\mathrm{S}$ test is most sensitive to shifts in the distributions of the two datasets being compared. It appeared to be an attractive test for analysis of our data because most of our CENTURY model runs produce output that are non-normally distributed and the $\mathrm{K}-\mathrm{S}$ test does not require that the datasets be normally distributed. 
The Kolmogorov-Smirnov test, despite its apparent strengths, turned out to be inappropriate for comparing sets of our data, but it was useful for comparing nonerosion simulations under different climate conditions against a normal curve. For comparisons between CENTURY output datasets, the K-S test yielded only two statistically significant comparisons of CENTURY runs: climate of 20 percent less than 1934 precipitation with no erosion vs. climate of 30 percent less than 1934 precipitation with $0.25 \mathrm{~mm}$ erosion $(\mathrm{p}=0.129)$ and climate of 20 percent less than 1934 precipitation with no erosion vs. climate of 30 percent less than 1934 precipitation with $0.50 \mathrm{~mm}$ erosion $(\mathrm{p}=0.060)$. These results do not logically make sense, since it should require a higher, not lower, level of drought to equal an erosion simulation. It is likely that the $\mathrm{K}-\mathrm{S}$ test found these two comparisons significant because one dataset in each comparison was highly skewed compared to the other; the resulting overlap of data values would make it appear as though the datasets were similar. We eliminated the $\mathrm{K}-\mathrm{S}$ test as a possibility for statistical comparison of our CENTURY model runs.

Next we turned to the possibility of using a test for differences in the mean values of two datasets. Two datasets could be highly skewed in the same direction and have similar means, a characteristic that would be difficult for the $\mathrm{K}-\mathrm{S}$ test to detect. The first test of means we considered using was Student's t-test, a commonly used test for similarity of mean values. However, a caveat of the t-test is that it is a parametric test and the data need to be normally distributed (Lehmann, 1975). We could make no such assumptions about the data, as we expected few of our CENTURY model run output data to have normal distributions. Therefore, we deemed the Student's t-test inappropriate for analysis of the CENTURY data and decided we would need a non-parametric test.

The Mann-Whitney $U$ test is a non-parametric version of the t-test (Gibbons and Chakraborti, 1992), and is better suited for comparison analyses of our data because the data do not need to be normally distributed as with the t-test. The M-W test is used on data that are from independent samples. The values from both groups are combined into one group and ranked from lowest to highest value (Conover, 1999). The rank order scores are then separated out into their original groups and the $\mathrm{U}$ statistic, or the number of times a value in the first group precedes a value in the second group, is calculated (Conover, 1999; Gibbons and Chakraborti, 1992). The significance of the $\mathrm{U}$ statistic, $\mathrm{p}$, is determined and for all $\mathrm{p}$ values greater than 0.05 , it is assumed that the two datasets being compared are similar. For our data, we used the SPSS program to perform all the necessary calculations for the Mann-Whitney $\mathrm{U}$ test and determine the corresponding $\mathrm{p}$ values. 


\section{Results}

\subsection{IMPACTS OF DROUGHT SEVERITY}

The control simulation reveals decreases of plant abundance [both aboveground biomass (shoots) and belowground biomass (roots and soil microbes)] during the 1930s and the 1950s drought events (Figure 2a). Despite this simulated vegetation decline in response to drought, consistent with observations of only minimal impacts on the vegetation landcover (Weaver, 1954; Weaver and Albertson, 1956), CENTURY simulated that these two droughts exerted negligible long-term impact on the ecosystem (Figure 3a). Mean and median aboveground biomass from 1938 to 1952 and from 1957 to 1989 are comparable to the 1904 to 1933 values (Table II.2), and two-sample Kolmogorov-Smirnov (K-S) tests of both aboveground and belowground carbon indicate these populations are statistically the same. The twentieth century droughts appear to have done little long-term damage to the Sand Hills ecosystem. Multiple decades of 1930s magnitude drought do not force CENTURY-predicted aboveground or belowground biomass to zero, but values drop below the pre-drought average (Figure 2b). Simulated belowground biomass retains its normal distribution curve (Figure 3b), but a one-sample KolmogorovSmirnov test reveals that this parameter differs more from a normal distribution than the control (Table III). Simulated aboveground biomass appears to shift to lower amounts and lose its normal distribution curve (Figure 3b); this result is confirmed by statistical tests (Table III). Aboveground biomass values between zero and $20 \mathrm{~g} / \mathrm{m}^{2}$ occur more frequently than in the control simulation (Figures $3 \mathrm{a}, \mathrm{b})$ and the $\mathrm{K}-\mathrm{S}$ two-tailed asymptotic significance value is zero when tested against the control (Table III), indicating no similarity between the extended 1930s drought simulation and the control run. Mild 1934-level drought will likely have some impact, but only on aboveground vegetation; this probably explains why most dunes did not remobilize during the 1930s Dust Bowl years.

The six sensitivity model studies with decreased 1934 precipitation in 10 percent increments up to 60 percent show a clear trend of aboveground biomass becoming less abundant with successively lower precipitation amounts (Figures $2 \mathrm{c}-\mathrm{h}, 3 \mathrm{c}-\mathrm{h}$ ), but never becoming zero. Belowground biomass retains its normal distribution curve through a 30 percent precipitation decrease (Figure 3e). With precipitation at 40 percent below 1934 values (Figure 3f) belowground live carbon starts to lose its normal distribution and Kolmogorov-Smirnov 2-tailed asymptotic significances are consistently zero (Table III). Aboveground biomass is more likely to be present at levels below $10 \mathrm{~g} / \mathrm{m}^{2}$ than above (Figures $2 \mathrm{f}-\mathrm{h}$ ). The loss of normal distribution is most visible when precipitation is reduced by 40 percent or more (Figures $3 \mathrm{f}-\mathrm{h}$ ). These results suggest that the precipitation threshold for noticeable impacts on the vegetation in the Sand Hills 50 percent $C_{3} / 50$ percent $C_{4}$ ecosystem is persistence of growing-season rainfall at 40 percent less than 1934 mild drought values. 
(a)

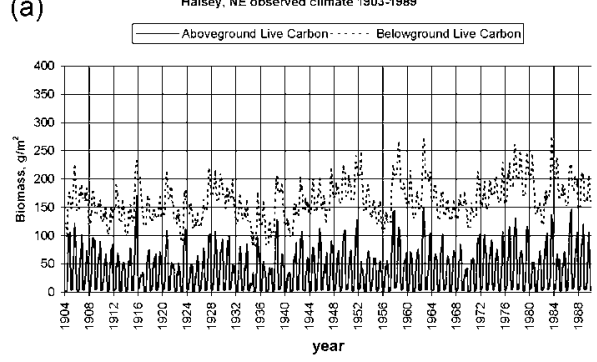

(C) Halsey, NE 1934 precipitation minus 10\% with natural variabuility, 19855.

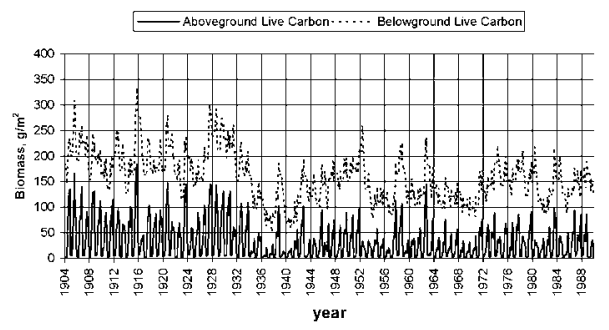

(e) Halsey, NE 1934 precipitation minus $30 \%$ with natural varizbility, 1995.

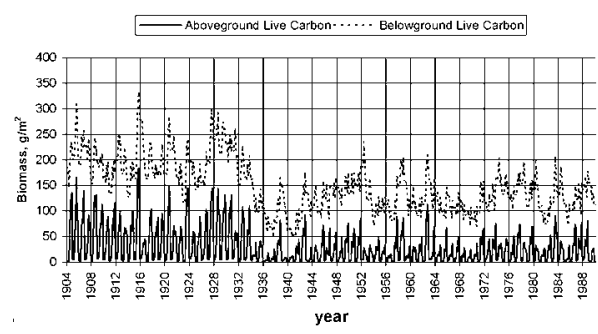

(g) Halsey, NE 1934 precipitation minus 50\%, 1935-1989

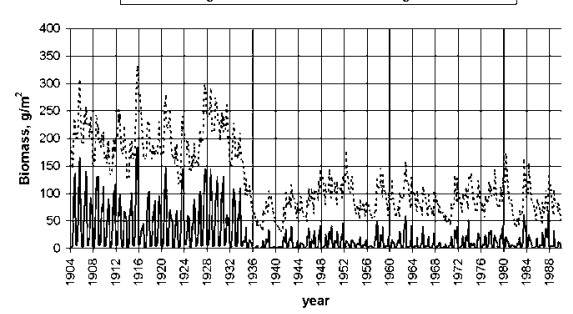

(b) Halsey, NE 1934 climate with natural variability from 1934 to 1989

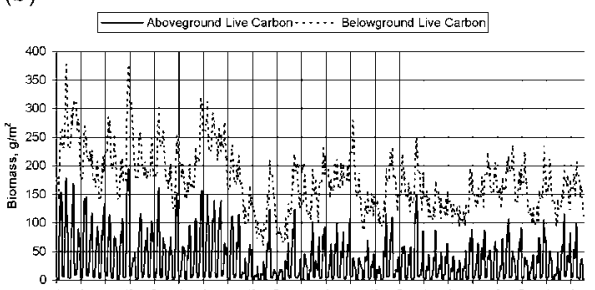

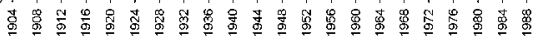

(d) Halsey, NE 1934 precipitation minus $20 \%$ with natural variabil ity, 1935 -

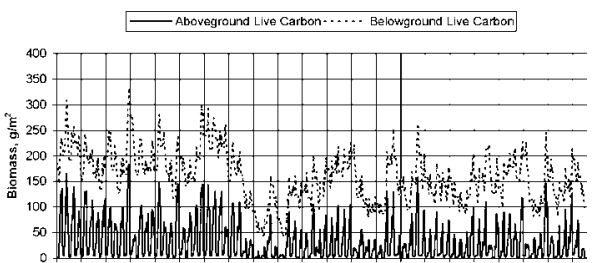

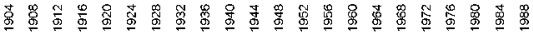

(f) Halsey, NE Observed climate, 1934 precipitation minus $40 \%$ with natura
variability, 1934-1989

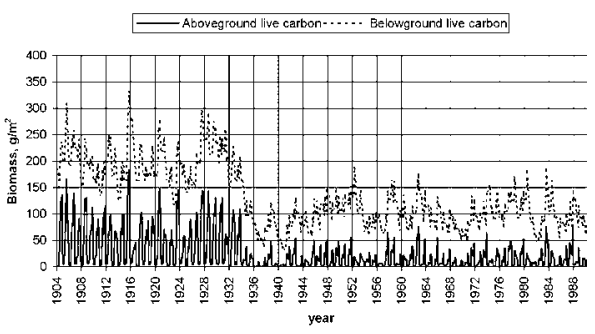

(h) Halsey, NE 1934 precipitation minus $60 \%, 1935-1989$

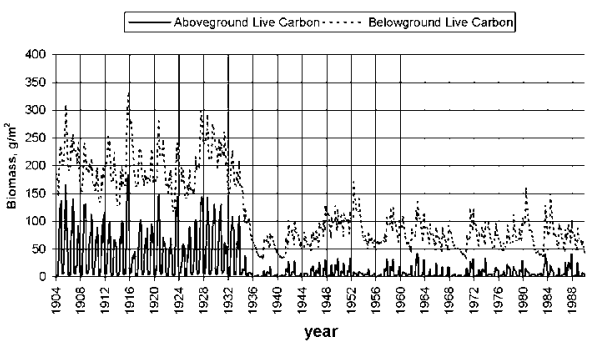

Figure 2. Time-series results of CENTURY model simulated aboveground and belowground carbon from 1904-1989. (a) Control run using observed climate data. (b) Experiment used observed data from 1904-1934 and 1935-1989 climate data rescaled to mean 1934 conditions, 1935-1989. (c) Experiment same as in 2(b) but precipitation data rescaled to have a mean equal to 90 percent of 1934 values. (d) Same as in 2(b) but precipitation data rescaled to have a mean equal to 80 percent of 1934 values. (e) Same as in 2(b) but precipitation data rescaled to have a mean equal to 70 percent of 1934 values. (f) Same as in 2(b) but precipitation data rescaled to have a mean equal to sixty percent of 1934 values. (g) Same as in 2(b) but precipitation data rescaled to have a mean equal to 50 percent of 1934 values. (h) Same as in 2(b) but precipitation data rescaled to have a mean equal to forty percent of 1934 values. Values are in grams per square meter. 
(a)

Halsey, NE Observed Glirriate, April through October, 1904-1989

aAboveground Live Carbon Belowground Live Carbon

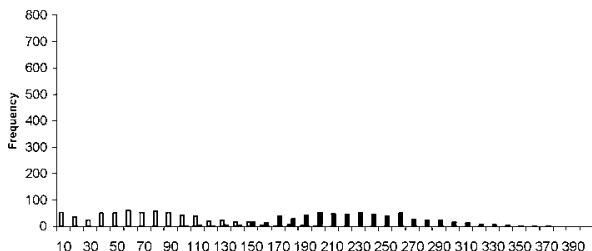

1030507090110130150170190210230250270290310330350370390 Biomass, gim

(C) Halsey, NE April through October biomass 1904-1989, 1934 precipitation minus $10 \%$ from $1935-1989$
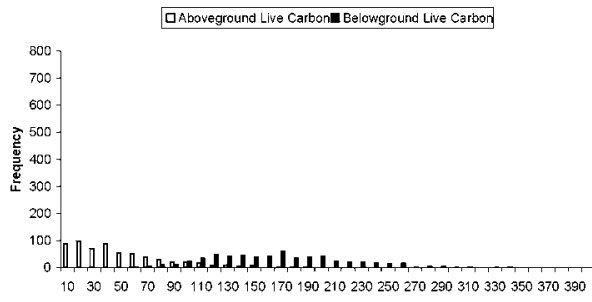
Biomass, $g \mathrm{gm}^{2}$ (e) Halsey, NE April through October biomass 1904-1989, 1934
precipitation minus $30 \%, 1935-1989$ 口Aboveground Live Carbonl Belowground Live Carbon

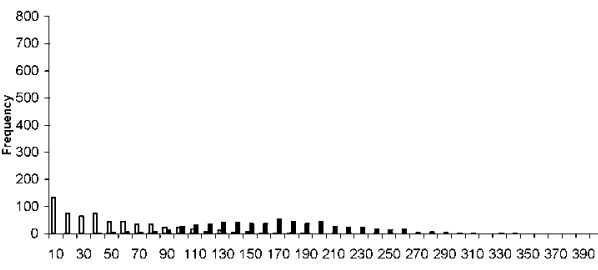
Biomass, $g^{\prime m^{2}}$

(g) Halsey, NE April through October biomass 1904-1989, 1934 precipitation minus 50\%, 1935-1989 口Aboveground Live Carbonn Belowground Live Carbor

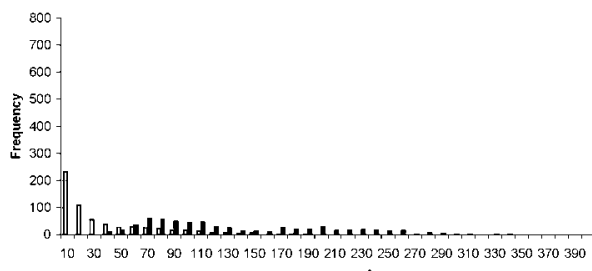

Biomass, $g / \mathrm{m}^{2}$ (b) Halsey, NE April through Octaber biomass, observed climate 1904-1934 perpefual 1934 climate with natural variability, 1935-1989

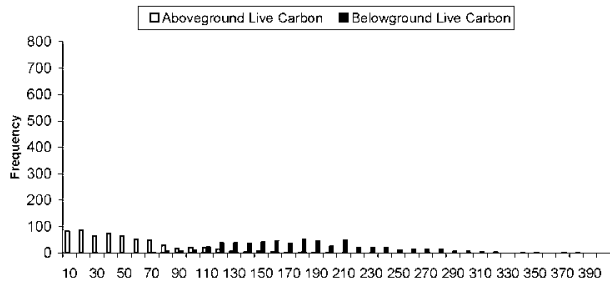
Biomass, $\mathbf{g}^{\prime} / \mathrm{m}^{2}$

(d) Halsey, NE April through October biomass 1904-1989, 1934 precipitation minus $20 \% 1935-198$

afboveground Live Carbond Eelowgeround Live Carbon

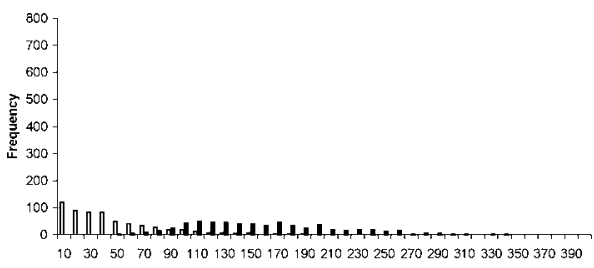
Biomass, $g^{\prime} \mathrm{m}^{2}$

(f) Halsey, NE April through October biomass 1904-1989, 1934 precipitation minus $40 \%, 1935-1989$

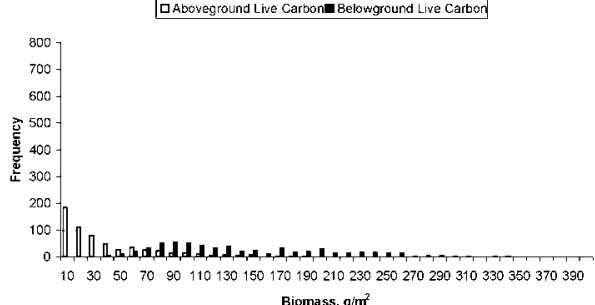

(h) Halsey, NE April through October biomass, 1904-1989, 1934 precipitation minus $60 \%$ 1935-1989 QAboveground Live Carbon Eelowground Live Carbon

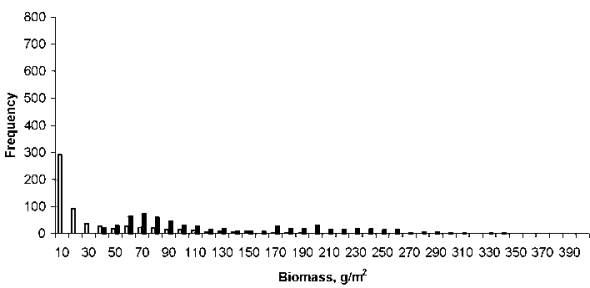

Figure 3. Frequency distribution plots of CENTURY aboveground and belowground live carbon model output for 1904-1989. (a) Control run using observed climate data. (b) Experiment used observed data from 1904-1934 and 1935-1989 climate data rescaled to mean 1934 conditions, 1935-1989. (c) Experiment same as in 3(b) but precipitation data rescaled to have a mean equal to 90 percent of 1934 values. (d) Same as in 3(b) but precipitation data rescaled to have a mean equal to 80 percent of 1934 values. (e) Same as in 3(b) but precipitation data rescaled to have a mean equal to 70 percent of 1934 values. (f) Same as in 3(b) but precipitation data rescaled to have a mean equal to sixty percent of 1934 values. (g) Same as in 3(b) but precipitation data rescaled to have a mean equal to 50 percent of 1934 values. (h) Same as in 3(b) but precipitation data rescaled to have a mean equal to forty percent of 1934 values. Values are grams per square meter. 
Table II

Mean and median values for aboveground live carbon and belowground live carbon for all model experiments. Values are in grams per square meter

\begin{tabular}{lllll}
\hline Model run & $\begin{array}{l}\text { Mean } \\
\text { aboveground }\end{array}$ & $\begin{array}{l}\text { Median } \\
\text { aboveground }\end{array}$ & $\begin{array}{l}\text { Mean } \\
\text { belowground }\end{array}$ & $\begin{array}{l}\text { Median } \\
\text { belowground }\end{array}$ \\
\hline Control, 50\%C3/C4, observed climate & 68,21 & 65,46 & 223,06 & 221,69 \\
Extended 1934 climate & 47,22 & 39,07 & 177,77 & 173,56 \\
1934 climate minus 10\% precipitation & 43,57 & 35,54 & 163,36 & 161,26 \\
1934 climate minus 20\% precipitation & 39,82 & 30,79 & 153,67 & 146,77 \\
1934 climate minus 30\% precipitation & 43,45 & 34,37 & 163,53 & 163,14 \\
1934 climate minus 40\% precipitation & 33,85 & 20,67 & 137,10 & 120,75 \\
1934 climate minus 50\% precipitation & 31,18 & 15,58 & 129,57 & 106,04 \\
1934 climate minus 60\% precipitation & 28,59 & 10,80 & 122,36 & 93,23 \\
Moderate grazing May through September & 60,83 & 57,33 & 229,47 & 229,00 \\
Fire every 3 years & 60,16 & 57,34 & 214,39 & 211,73 \\
C3 plants 25\%, C4 plants 75\% after 1935 & 66,46 & 63,13 & 222,85 & 219,79 \\
C3 plants 75\%, C4 plants 25\% after 1935 & 62,70 & 59,92 & 195,83 & 193,97 \\
C3 plants 100\% after 1935 & 62,65 & 59,48 & 516,93 & 517,51 \\
C4 plants 100\% after 1935 & 60,47 & 54,01 & 364,04 & 361,85 \\
\hline
\end{tabular}

Mean and median aboveground live carbon values become increasingly dissimilar with a greater reduction of precipitation and we see a difference of $15.60 \mathrm{~g} / \mathrm{m}^{2}$ at 50 percent precipitation reduction and $17.79 \mathrm{~g} / \mathrm{m}^{2}$ at sixty percent precipitation reduction (Table II). When precipitation is 60 percent less than in 1934, simulated aboveground vegetation is sparse at mostly $10 \mathrm{~g} / \mathrm{m}^{2}$ or less, but it never completely disappears (Figures $2 \mathrm{~h}$ and $3 \mathrm{~h}$ ). Mean belowground live carbon values with a 60 percent precipitation reduction differ from the control by $100.70 \mathrm{~g} / \mathrm{m}^{2}$ (Table II) but never become zero (Figure $2 \mathrm{~h}$ ). The Kolmogorov-Smirnov p value is zero for a test against the control of belowground live carbon under a sixty percent precipitation regime (Table III), indicating lack of similarity between the two datasets.

Soil nitrogen amounts were also plotted for the above model simulations (Figure 4). The soil nitrogen pool in the model has reached equilibrium and leveled off at about $242 \mathrm{~g} / \mathrm{m}^{2}$ after a 2000-year spin up period using stochastic climate. Introducing a file of observed weather to replace the stochastic climate causes soil nitrogen to steadily decline in the control simulation (Figure 4a). The nitrogen decline is also apparent when precipitation is decreased up to 30 percent less than 1934 conditions, but there is an initial small soil nitrogen increase of about $2 \mathrm{~g} / \mathrm{m}^{2}$ around the initiation of the drought in 1934. For the remaining three simulations where precipitation is decreased 40, 50, and 60 percent from 1934, soil nitrogen rapidly increases starting in 1934, but levels off after about 10 years. The nitro- 


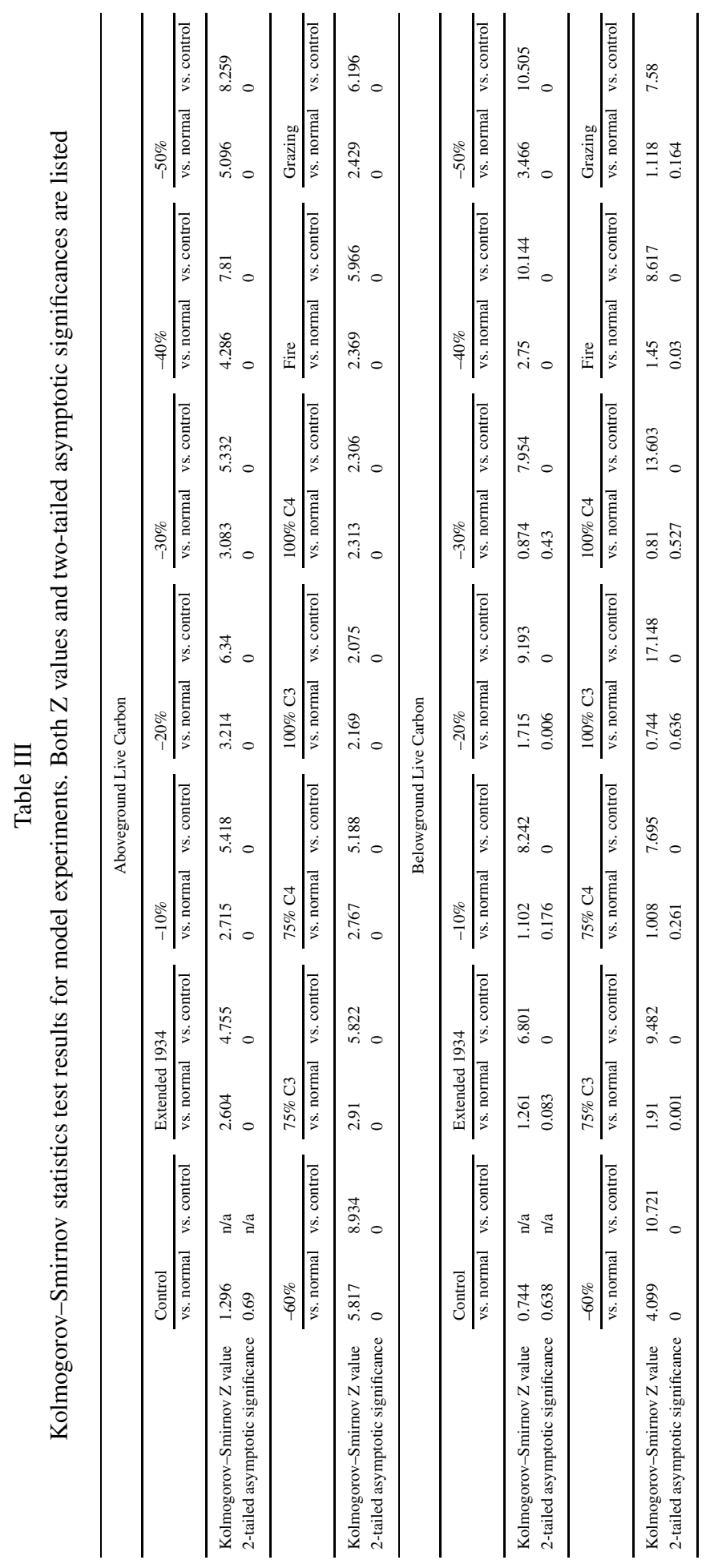


(a) Soil Nitrogen, Halsey, NE observed climate 1903-1989

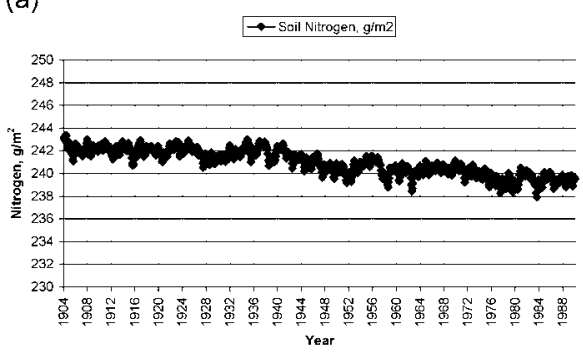

(C) Soil Nitrogen, Halsey, NE observed climate 1903-1933, 1934 precipitation minus 10 percent 1934-1989 $\rightarrow-$ Soil Nitrogen, g/m2

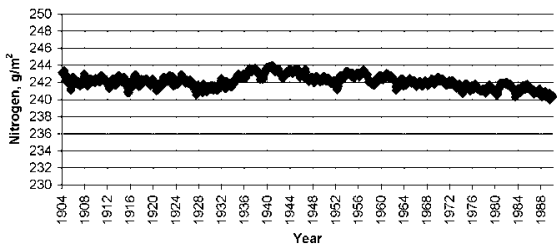

(e) Halsey, NE observed climate 1903-1933, 1934 precipitation minus 30 percent 1934-1989 $\rightarrow-$ Soil Nitrogen, g/m2

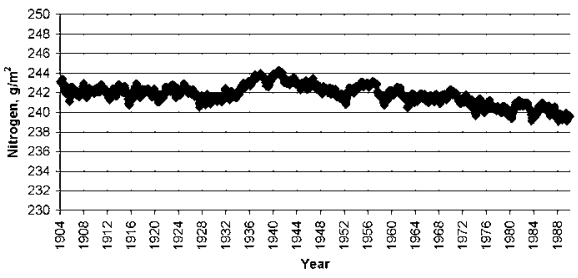

(g) Hałsey, NE observed climate 1903-1933, 1934 precipitation minus 50 percent 1934-1989

$$
\rightarrow \text { Soil Nitrogen, } g / m 2
$$

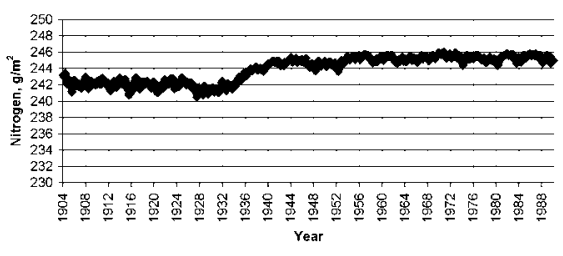

(b) Halsey, NE observed climate 1903-1933, 1934 precipitation

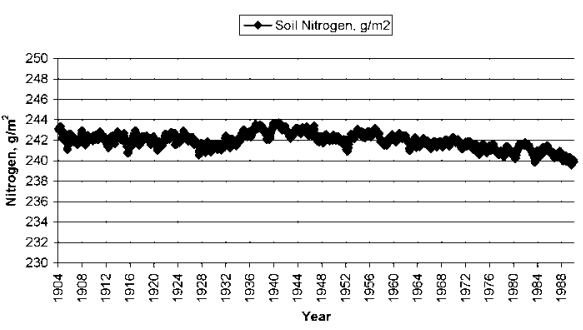

(d) Halsey, NE observed climate 1903-1933, 1934 preciptation minus 20 percent $1934-1989$

$\rightarrow$ Soil Nitrogen, gim2

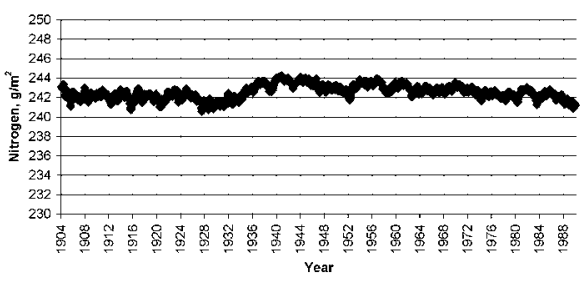

(f) Halsey, NE observed climate 1903-1933, 1934 precipitation minus 40 percent 1934-1989 $\rightarrow-$ Soil Nitrogen, glma

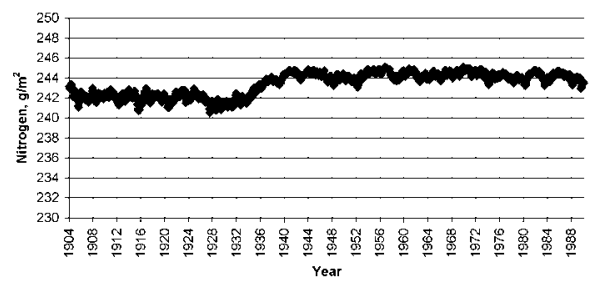

(h) Halsey, NE observed climate 1903-1933, 1934 precipitation

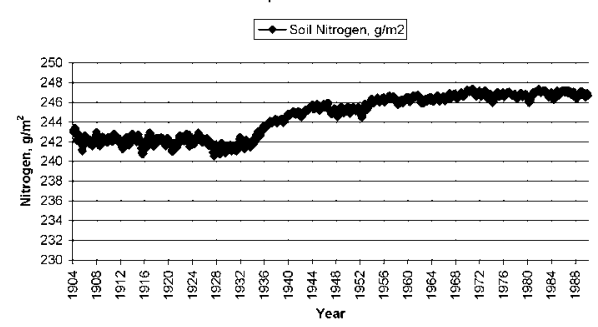

Figure 4. CENTURY-simulated soil nitrogen values for the control simulation with 20th Century obserbed climate (a) and different drought severities beginning in 1934 (b-h). Prior to 1934, nitrogen is at an equilibrium value after a 2000 -year model spin-up. 
gen reaches a maximum value of about $247 \mathrm{~g} / \mathrm{m}^{2}$ in the 60 percent precipitation reduction experiment.

Eroding the soil $0.25 \mathrm{~mm} / \mathrm{month}$ per year from January through April will cause less than one meter of total soil erosion per century, an amount that is conservative according to field-derived estimates (S. Forman, personal communication). Yet this amount appears to be too much in CENTURY runs. Mann-Whitney statistical comparisons of non-erosion CENTURY simulations with different levels of drought and erosion simulations with different levels of drought and erosion show that only $0.25 \mathrm{~mm}$ per month of erosion with a climate extended at 1934 levels is equivalent to an extended drought with precipitation 20 percent less than in 1934 (Table IV). Figure 5 shows that soil erosion by itself or in conjunction with drought impacts both aboveground and belowground live carbon amounts more than drought alone, as would be expected. The control simulation using observed 20th century climate with soil erosion (Figure 5a) shows that upon initiating erosion in 1934, amounts of aboveground and belowground live carbon drop to far below the values seen for the observed climate simulation without erosion (Figure 2a), and are actually comparable to the results seen where precipitation is reduced 20 percent from 1934 amounts without erosion (Figure 2f). The relationship between the 20 percent precipitation reduction simulation and the erosion simulation becomes more evident when viewing frequency distribution plots of April through October biomass (Figure 6). A precipitation decrease of 40 percent from the 1934 mean yields a frequency distribution plot (Figure 3f) that closely resembles the plot when precipitation is not reduced but the soil is eroded (Figure 6a). These results suggest that when the land loses topsoil to wind erosion during a drought, there will be significantly more impact on vegetation abundances than from drought without erosion.

Kolmogorov-Smirnov test results are similar for the erosion experiments (Table V) and the non-erosion experiments (Table III) when values are compared to a normal distribution. The erosion experiments, however, show less statistical difference from the erosion control simulation (Table V), which is where the soil is eroded under 20th century observed climate conditions. These results suggest that erosion itself is effective in disturbing the ecosystem, and further disruptions, such as reduced precipitation, are of less importance when combined with erosion than when they occur alone. In the event of a drought, initiation of erosion will cause the vegetation community to decline more rapidly than if erosion does not occur.

Soil nitrogen was also plotted for all drought with $1 \mathrm{~mm}$ erosion simulations. For all 8 experiments, from control climate through 60 percent precipitation reduction from 1934, soil nitrogen exhibited the same pattern and the values were consistent regardless of the severity of drought (Figure 7). Nitrogen remains at its steady state from the model spin-up until 1934, when January through April erosion is introduced to the model. The erosion parameter in CENTURY does not remove vegetation. The carbon and nitrogen removed from the model simulations by the erosion subroutines comes from soil organic matter pools and belowground metabolic and structural pools. Eroding the soil $1 \mathrm{~mm}$ monthly from January 


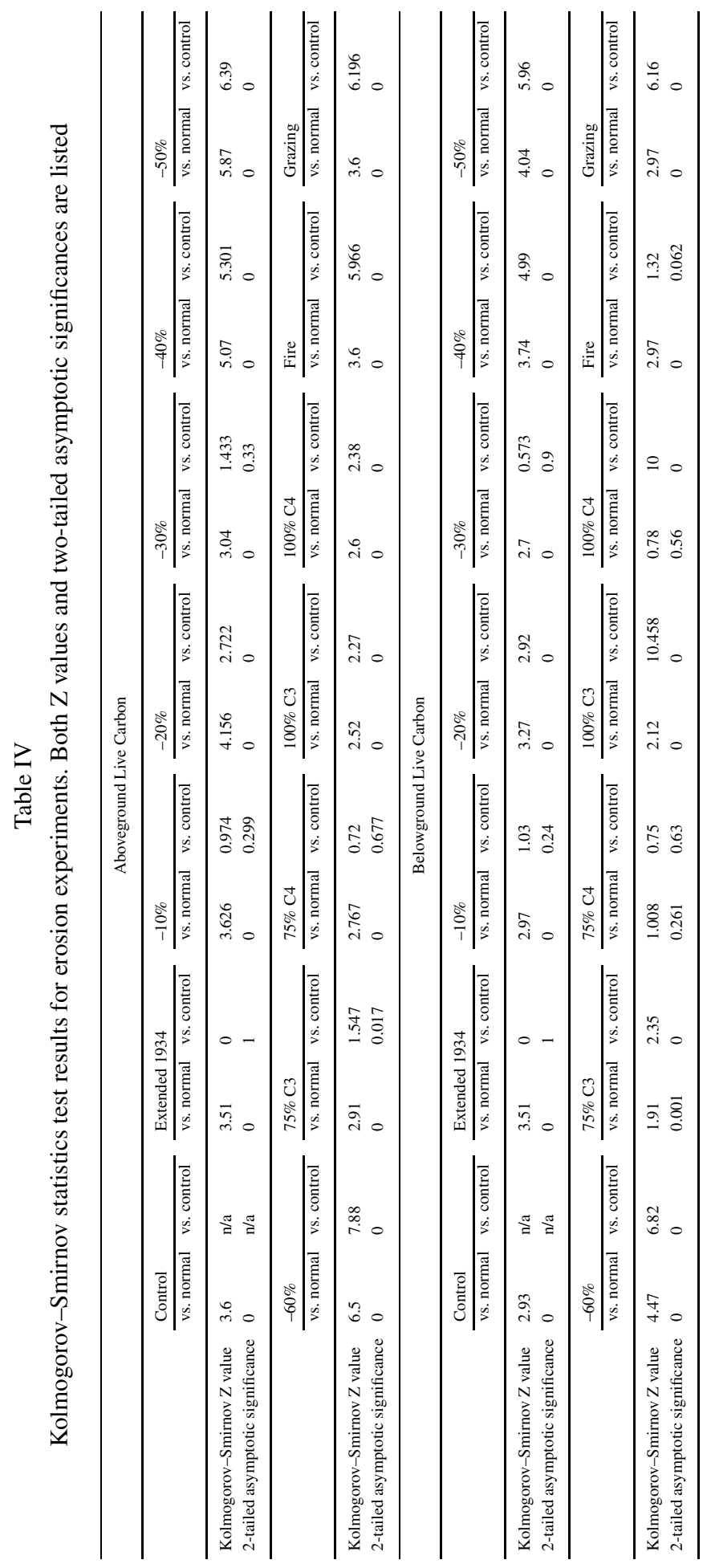


(a)

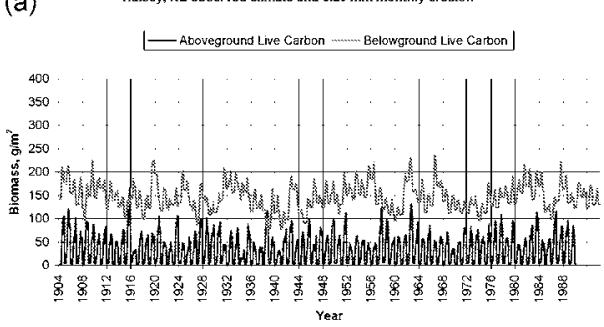

(C) Halsey, NE 1934 precipitation minus to percent and $0.25 \mathrm{~mm}$ monthly

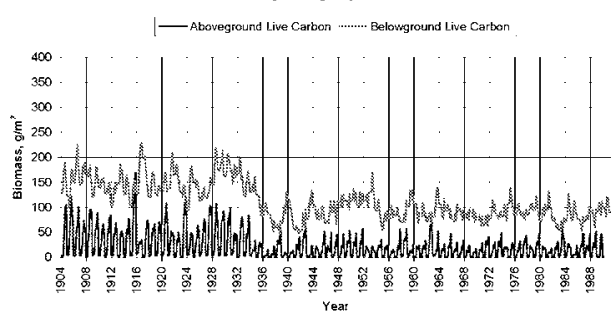

(e) Halsey, NE 1934 precipitation minus 30 percent and $0.25 \mathrm{~mm}$ monthly
soil erosion danuary through April, 1934-1989

| Abovegrourd Live Carbon …-...-Belowground Live Carbon

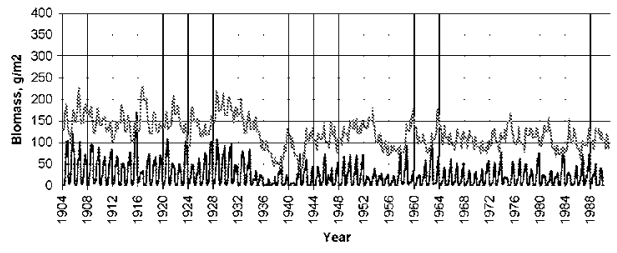

(g) Halsey, NE 1934 prectiptation minus 50 percent and $0.25 \mathrm{~mm}$ monenty sofl erosion

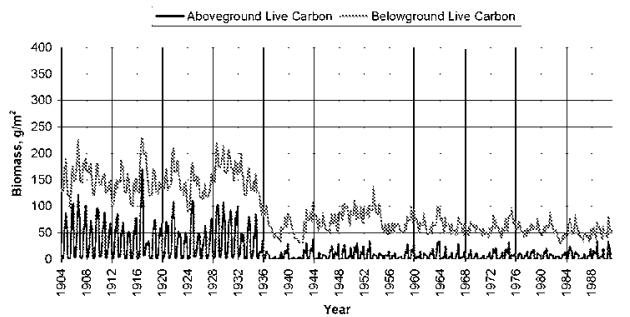
(b) Halsey. NE extended 1934 climate and 0.25 mm monthly soil erosion January

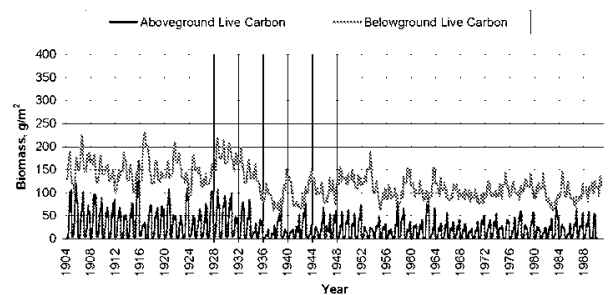

(d)

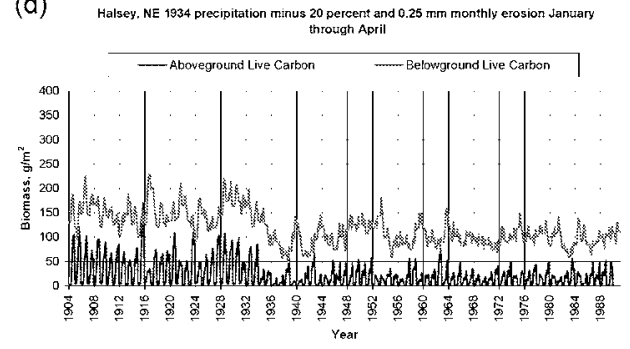
(f) Halsey, NE 1934 precipitation minus 4 4C percent and 0.25 mm monthly soil erosion
January throught April, 1934-1989 -Aboveground Live Carbon …-...Betlowground Live Carbon

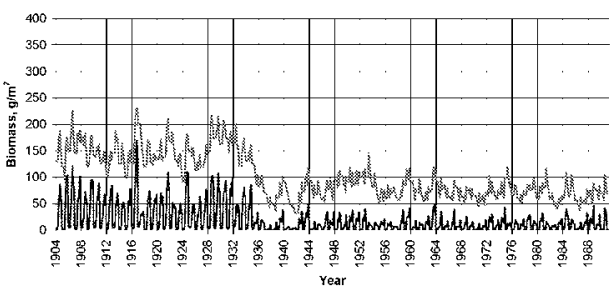

(h) Halsey, NE 1934 pree fpltaction minus 60 percent and $0.25 \mathrm{~mm}$ manthily soll erosion.

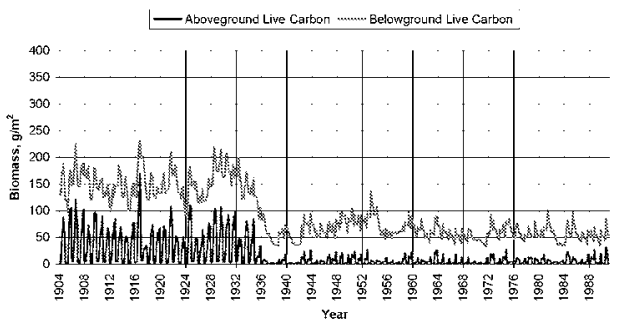

Figure 5. CENTURY-simulated aboveground and belowground live carbon for observed 20th Century climate (a) and various intensities of drought. Erosion occurs every year between 1934 and 1989, and the erosion routine removes $0.25 \mathrm{~mm}$ of soil per month from January through April ( $1 \mathrm{~mm} / \mathrm{year}$ ). The control erosion simulation with observed climate (a) is comparable to the non-erosion simulation with 20 percent precipitation reduction (Figure $2 \mathrm{f}$ ). 
(a) Halsey, NE observed climate, $0.25 \mathrm{~mm}$ monthly erosion

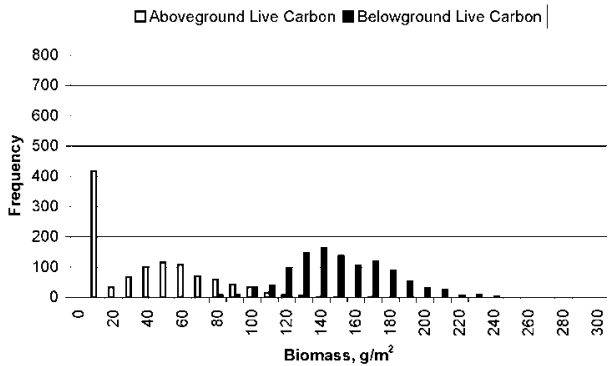

(C) Halsey, NE 1934 precipitation minus 10 percent and $0.25 \mathrm{~mm}$ monthly erosion

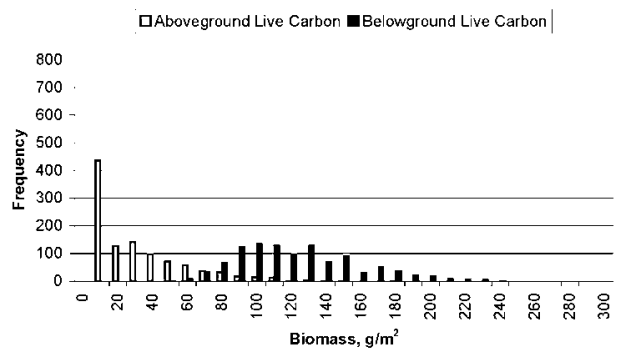

(e) Halsey, NE 1934 precipitation minus 30 percent with $0.25 \mathrm{~mm}$ monthly erosion

| Aboveground Live Carbon Belowground Live Carbon

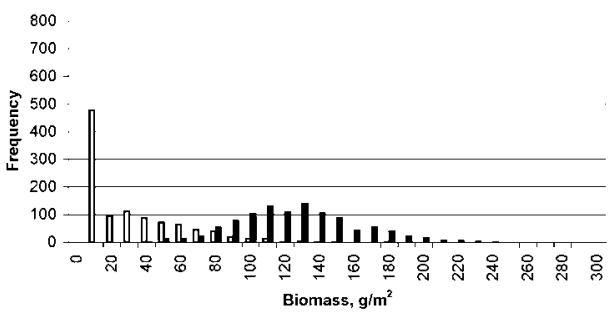

(g) Halsey, NE 1934 precipitation minus 50 percent and $0.25 \mathrm{~mm}$ monthly erosion

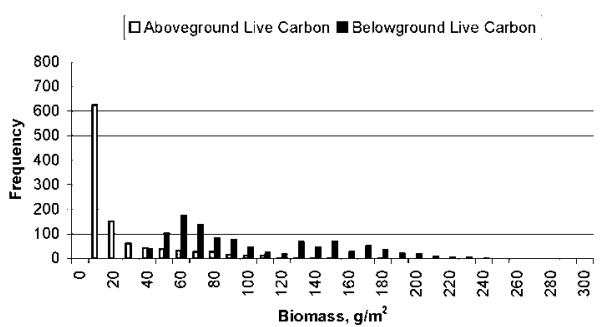

(b) Halsey, NE 1934 precipitation extended, $0.25 \mathrm{~mm}$ monthly erosion

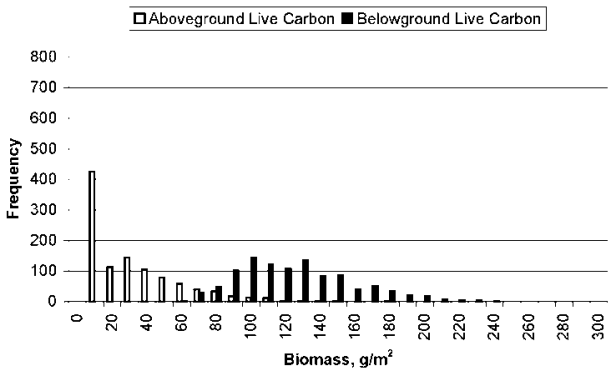

(d) Halsey, NE 1934 precipitation minus 20 percent and $0.25 \mathrm{~mm}$ monthly erosion

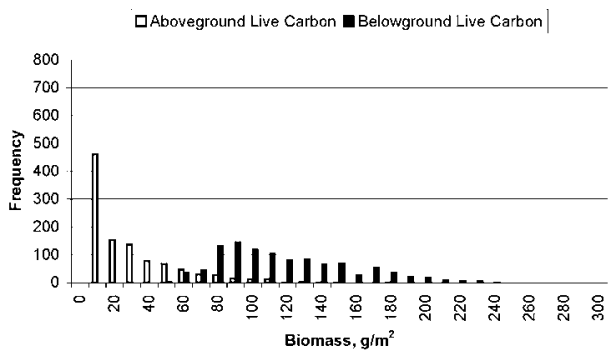

(f) Halsey, NE 1934 precipitation minus 40 percent, $0.25 \mathrm{~mm}$ monthly erosion

[aboveground Live Carbon @Belowground Live Carbo

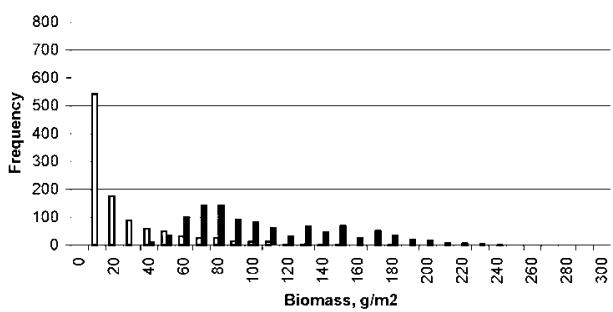

(h) Halsey, NE 1934 precipitation minus 60 percent and $0.25 \mathrm{~mm}$ monthly erosion

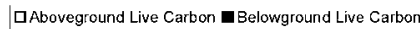

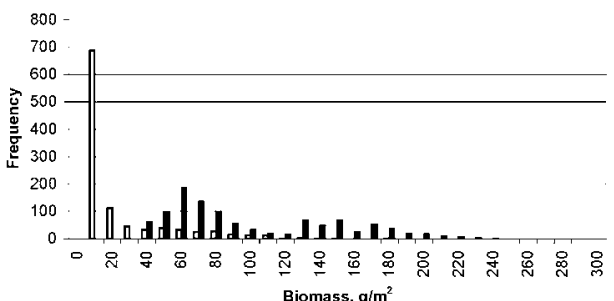

Figure 6. Frequency distribution for aboveground and belowground live carbon values in Figure 2.5. January through April $0.25 \mathrm{~mm}$ monthly erosion is initiated in 1934 and continues through 1989. Erosion appears to cause biomass to favor lower values even without climatic disturbance (a). 
Table V

Summary of Mann-Whitney U test significant results and one insignificant result for comparisons of CENTURY model runs for 20th century climate from 1904-1999. The amount of erosion specified is monthly from January through April and the precipitation decrease indicated was initiated in 1934. Erosion of $0.25 \mathrm{~mm}$ monthly, or $1 \mathrm{~mm}$ per year, is the equivalent of an extended drought $20 \%$ more severe than that which occurred in the 1930s in Nebraska. Increased erosion in the model does not yield significant results other than those seen here, and these are not as good as if there is only $0.25 \mathrm{~mm}$ erosion

\begin{tabular}{ll}
\hline Model runs compared & Mann-Whitney $\mathrm{p}(\mathrm{p}<0.05=$ no similarity $)$ \\
\hline $\begin{array}{l}1934 \text { precipitation }-20 \% \text { vs. extended } \\
1934 \text { climate and } 0.25 \mathrm{~mm} \text { erosion }\end{array}$ & 0.673 \\
1934 precipitation $-20 \%$ vs. extended & \\
1934 climate and $0.50 \mathrm{~mm}$ erosion & 0.199 \\
1934 precipitation $-20 \%$ vs. extended & \\
1934 climate and $0.75 \mathrm{~mm}$ erosion & 0.025 \\
1934 precipitation $-30 \%$ vs. extended & \\
1934 climate and $0.25 \mathrm{~mm}$ erosion & 0.054 \\
\hline
\end{tabular}

through April of every year causes an initial steady increase in $\mathrm{N}$ from its equilibrium value of approximately $241 \mathrm{~g} / \mathrm{m}^{2}$ to a maximum of approximately $263 \mathrm{~g} / \mathrm{m}^{2}$ in ten years. Soil $\mathrm{N}$ then starts a steady decline and reaches its original equilibrium value in another ten years, but continues to decrease until it has reached a value of about $130 \mathrm{~g} / \mathrm{m}^{2}$ fifty years after the initiation of erosion. CENTURY simulations of these erosion conditions with various decreased amounts of precipitation show that precipitation does not affect soil nitrogen values (Figure 7).

\subsection{IMPACTS OF GRAZING}

Low-intensity summer grazing under observed climate conditions has little influence on model-predicted biomass (Table II). Introduction of grazing to an already drought-stressed environment, however, decreases live biomass more than mild drought alone (Figure 8a, Table II). Mean aboveground live carbon under an extended 1934 drought is $47.22 \mathrm{~g} / \mathrm{m}^{2}$ but drops to $28.53 \mathrm{~g} / \mathrm{m}^{2}$ with the addition of low-intensity summer grazing, and the Kolmogorov-Smirnov $\mathrm{p}$ value of zero (Table II.3) indicates lack of similarity to the control. Belowground carbon maintains a normal distribution but the $\mathrm{K}-\mathrm{S} \mathrm{p}$ value is zero relative to the control (Table III), indicating dissimilarity in belowground live carbon between control and grazing situations. Low-intensity grazing coupled with drought will impact both above- 


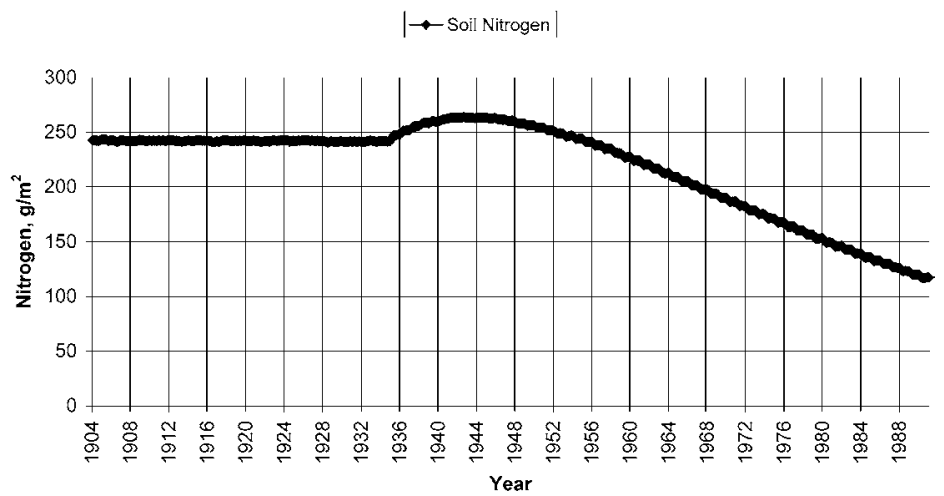

Figure 7. Soil nitrogen when $0.25 \mathrm{~mm}$ monthly January through April soil erosion is initiated in 1934. This pattern of nitrogen depletion occurs regardless of climate or other environmental factors with erosion.

ground and belowground biomass, but the stability of the rooting systems will not be affected as much as the shoots.

Soil nitrogen in the grazing simulation follows the pattern seen for situations of mild drought (Figures 10a and 4a). There is an initial small increase in nitrogen of about $2 \mathrm{~g} / \mathrm{m}^{2}$, and then a steady decline over the next 50 years (Figure 10a). Soil nitrogen is about $240 \mathrm{~g} / \mathrm{m}^{2}$ in 1989 , whereas its initial value in 1903 is about $242 \mathrm{~g} / \mathrm{m}^{2}$. Soil nitrogen in the CENTURY model is apparently responding more to other environmental and climatic factors than to an imposed grazing regime.

\subsection{IMPACTS OF FIRE}

A fire regime that removes 60 percent of aboveground biomass every three years does not alter CENTURY-predicted vegetation abundance significantly under observed climate conditions (Table II). However, coupling regular fire events with extended drought serves to diminish aboveground live carbon and shoot biomass frequencies favor lower values (Figure 9b, Table II), suggesting that plant shoots cannot persist under the dual stresses of drought and fire. Statistical tests of fire and drought stressed aboveground live carbon against control aboveground live carbon reveal $\mathrm{K}-\mathrm{S} \mathrm{p}$ values of zero, confirming that fire and drought stressed communities bear little similarity to the control situation (Table III). Aboveground live carbon under fire and drought stresses is reduced to less than half the value for fire alone (Table II). Belowground live carbon decreases, but maintains a normal distribution, suggesting that coupling fire and drought does not upset the balance of underground portions of the ecosystem.

Soil nitrogen is negatively affected by fire events every 3 years that remove 60 percent of the vegetation. Soil nitrogen steadily declines throughout the duration of the 86-year CENTURY simulation with fire and 1934 precipitation persisting 
(a) Halsey, NE, observed climate 1904-1934, 1934 climate extended through 1989, biomass values Apri through October, grazing May - September

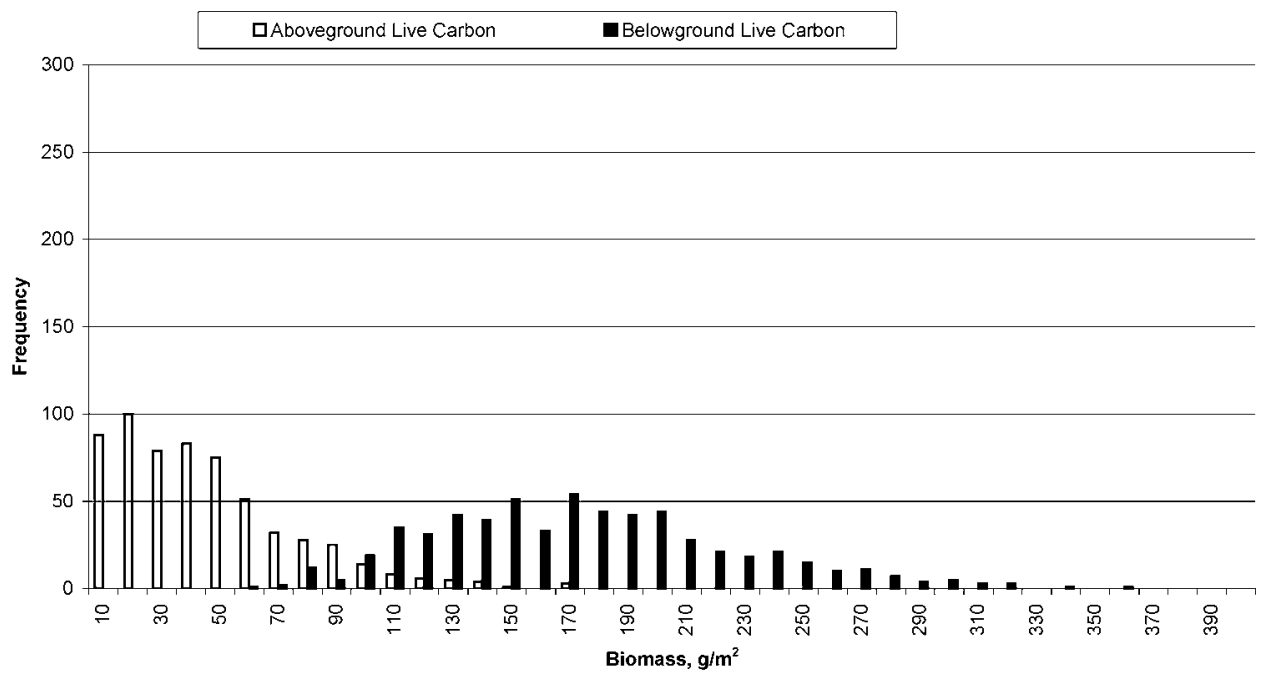

(b) Halsey, NE, observed climate 1904-1934, 1934 climate extended through 1989, biomass values Apri through October, cold fire every 3 years

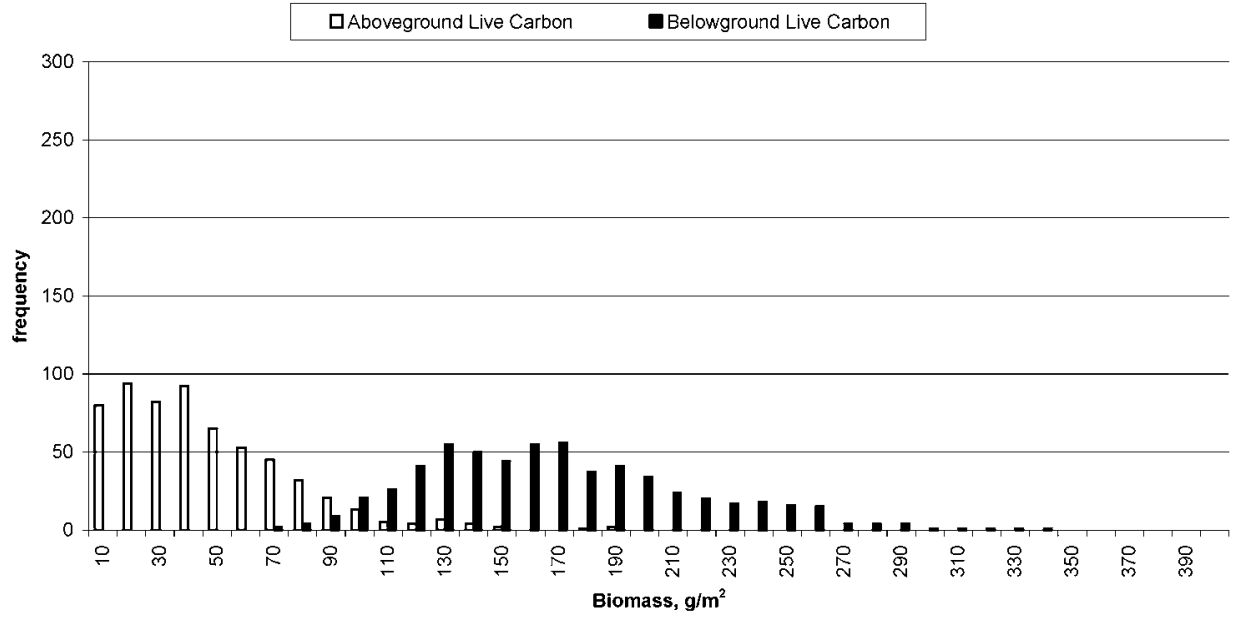

Figure 8. Frequency distribution plots of CENTURY aboveground and belowground live carbon model output for 1904-1989. (a) Experiment used observed data from 1904-1934 and 1935-1989 climate data rescaled to mean 1934 conditions for 1935-1989 and annual May-September low-intensity grazing with a linear effect on production. (b) Experiment used observed data from 1904-1934 and 1935-1989 climate data rescaled to mean 1934 conditions for 1935-1989 and fire which removes sixty percent of aboveground biomass every third year. 
(a) Halsey, NE, observed climate 1904-1934, 1934 climate extended through 1989, biomass values Apri through October, grazing May - September

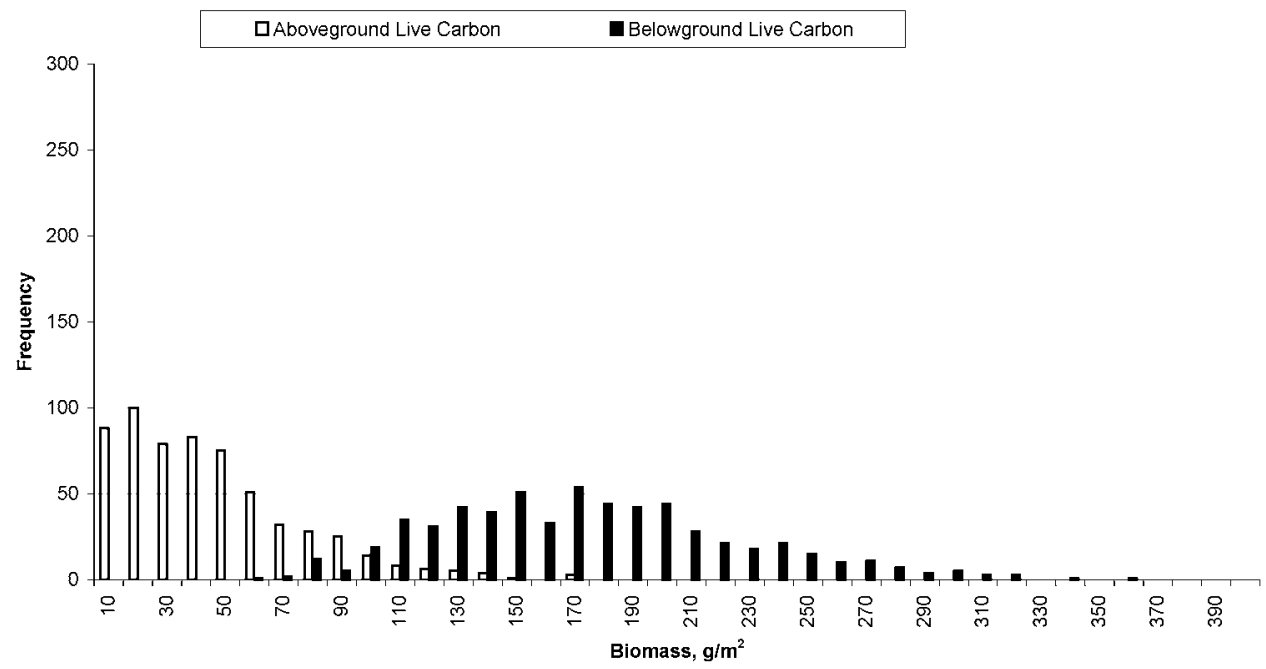

(b) Halsey, NE, observed climate 1904-1934, 1934 climate extended through 1989, biomass values Apri through October, cold fire every 3 years

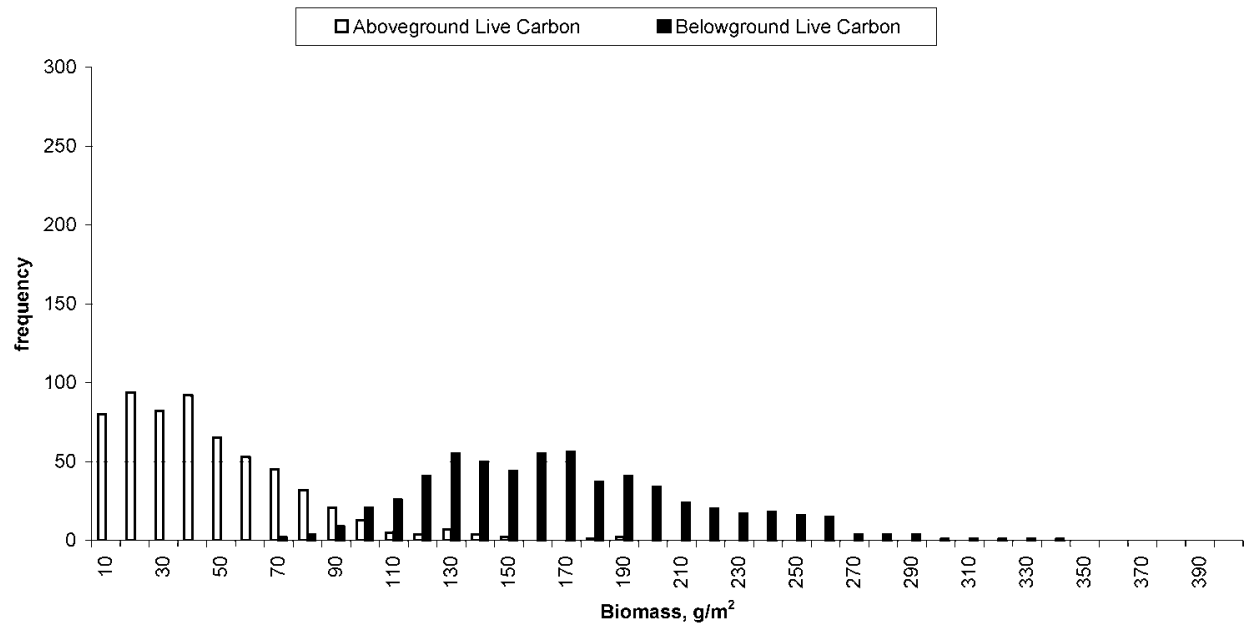

Figure 9. Frequency distribution plots of CENTURY aboveground and belowground live carbon model output for 1904-1989. (a) Experiment used observed data from 1904-1934 and 1935-1989 climate data rescaled to mean 1934 conditions for 1935-1989 and annual May-September low-intensity grazing with a linear effect on production. (b) Experiment used observed data from 1904-1934 and 1935-1989 climate data rescaled to mean 1934 conditions for 1935-1989 and fire which removes sixty percent of aboveground biomass every third year. 
(a) Halsey, NE observed climate 1903-1933, 1934 precipitation 19341989, moderate intensity grazing May through September

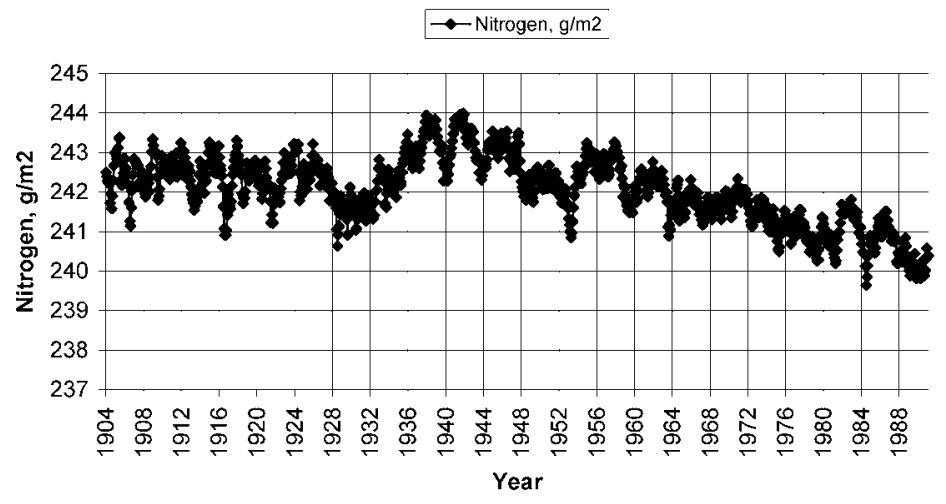

(b) Halsey, NE observed climate 1903-1933, 1934 precipitation 19341989 , fire event with $60 \%$ vegetation removal every 3 years

$\rightarrow-$ Soil Nitrogen, $g / m 2$

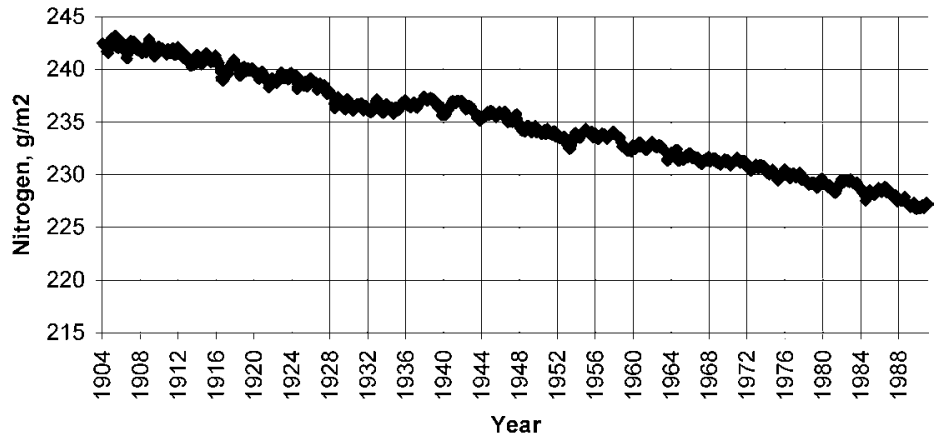

Figure 10. Soil nitrogen dynamics under extended 1934 climate conditions and (a) Moderate grazing and (b) fire every 3 years. Fire causes a greater reduction in soil nitrogen than grazing, most likely because grazing animals are returning organic nitrogen to the soil.

through 1989 (Figure 10b). Although we see a decline in soil nitrogen for the control simulation (Figure 4a), addition of fire to the environment appears to dampen the soil's ability to incorporate nitrogen after the addition of a disturbance such as drought or the fire is removing enough plant material that negligible amounts of nitrogen are available to be absorbed by the soil.

\subsection{IMPACTS OF PLANT FUNCTIONAL TYPE}

Changing the $\mathrm{C}_{3} / \mathrm{C}_{4}$ ratio in CENTURY to 75 percent/25 percent and maintaining naturally-variable 1934 climate through 1989 decreased both simulated mean aboveground live carbon and belowground live carbon. Mean aboveground live carbon decreased by $16.46 \mathrm{~g} / \mathrm{m}^{2}$ and belowground live carbon decreased by 31.95 $\mathrm{g} / \mathrm{m}^{2}$ relative to the prolonged 1934 drought simulation, which had a 50 percent $/ 50$ 
percent $\mathrm{C}_{3} / \mathrm{C}_{4}$ ratio (Table II). Similarity of aboveground live carbon under extended drought conditions with 75 percent $C_{3}$ plants vs. 50 percent $C_{3}$ plants appears to be only slightly different based on absolute numbers, but a $\mathrm{K}-\mathrm{S}$ p value of zero shows that the control is significantly different (Table III).

Some portions of the Sand Hills also have (or likely had) compositions that favored $\mathrm{C}_{4}$ over $\mathrm{C}_{3}$ plants due to hot, dry summer conditions. Running the model with 75 percent $\mathrm{C}_{4}$ plants and 1935-1989 climate rescaled to 1934 values (Figure 11b) changes values of both aboveground and belowground biomass from the extended 1934 climate simulation (50 percent $C_{3}, 50$ percent $C_{4}$ ) by only 14.80 $\mathrm{g} / \mathrm{m}^{2}$ and $14.71 \mathrm{~g} / \mathrm{m}^{2}$, respectively (Table II). However, statistical tests reveal that altering the ecosystem from a 50 percent $\mathrm{C}_{4}$ plant composition to 75 percent $\mathrm{C}_{4}$ plants has noticeable effects on both aboveground and belowground live carbon (Table III). K-S p values for tests against the control for both variables are zero (Table III).

Plant functional type composition has an effect on soil nitrogen as well as plant biomass. When the ecosystem shifts to 75 percent $C_{3}$ plants in response to drought, soil nitrogen steadily declines and does not recover (Figure 12a). Between 1934 and 1989 , soil $\mathrm{N}$ declines from about $242 \mathrm{~g} / \mathrm{m}^{2}$ to $234 \mathrm{~g} / \mathrm{m}^{2}$, a loss of roughly $8 \mathrm{~g} / \mathrm{m}^{2}$. However, we do not see this decline when the ecosystem is altered to contain 75 percent $\mathrm{C}_{4}$ species and 25 percent $\mathrm{C}_{3}$ species (Figure 12b). Soil nitrogen remains fairly steady, and from 1934 to 1989 , decreases by only about $2 \mathrm{~g} / \mathrm{m}^{2}$. These results suggest that $\mathrm{C}_{3}$ species could be using more of the available nutrients in the soil than $\mathrm{C}_{4}$ species do. Since $\mathrm{C}_{3}$ plants tend to be rhizomatous whereas $\mathrm{C}_{4}$ species are generally bunch grasses that do not spread their rooting systems laterally (Symstad and Tilman, 2001), it is likely we are seeing the effects of these plant functional type differences on soil nitrogen.

When plant functional type is specified as 100 percent $C_{3}$ and climate as 1934 conditions with natural variability from 1935 through 1989 after 1934, aboveground live carbon becomes sparser than it does in the extended 1934 climate simulation by $16.67 \mathrm{~g} / \mathrm{m}^{2}$ (Table II). In contrast, belowground live carbon increases to $87.27 \mathrm{~g} / \mathrm{m}^{2}$ more than in the perpetual 1934 climate simulation (Table II). Comparisons between the $\mathrm{K}-\mathrm{S} \mathrm{p}$ values for this model run vs. the control for aboveground live carbon in the extended 1934 and 100 percent $\mathrm{C}_{3}$ simulations show that both of these runs are different from the control, with values of zero (Table III). Belowground live carbon under drought and 100 percent $\mathrm{C}_{3}$ conditions is also statistically significant. The p value vs. the control is zero, where the extended 1934 simulation's p value vs. the control is significant at 0.083 (Table III). Altering the ecosystem to have only one plant functional type (either $\mathrm{C}_{3}$ or $\mathrm{C}_{4}$ ) thus appears to have the greatest effect on belowground live carbon.

Specifying 100 percent $C_{4}$ plants and 1934 climate with natural variability from 1935 to 1989 causes aboveground live carbon to decrease by $16.80 \mathrm{~g} / \mathrm{m}^{2}$, similar to what is seen when the ecosystem becomes 100 percent $\mathrm{C}_{3}$ species (Table II). The aboveground carbon $K-S$ p values are zero for 100 percent $C_{3}$ or 100 percent $C_{4}$ 


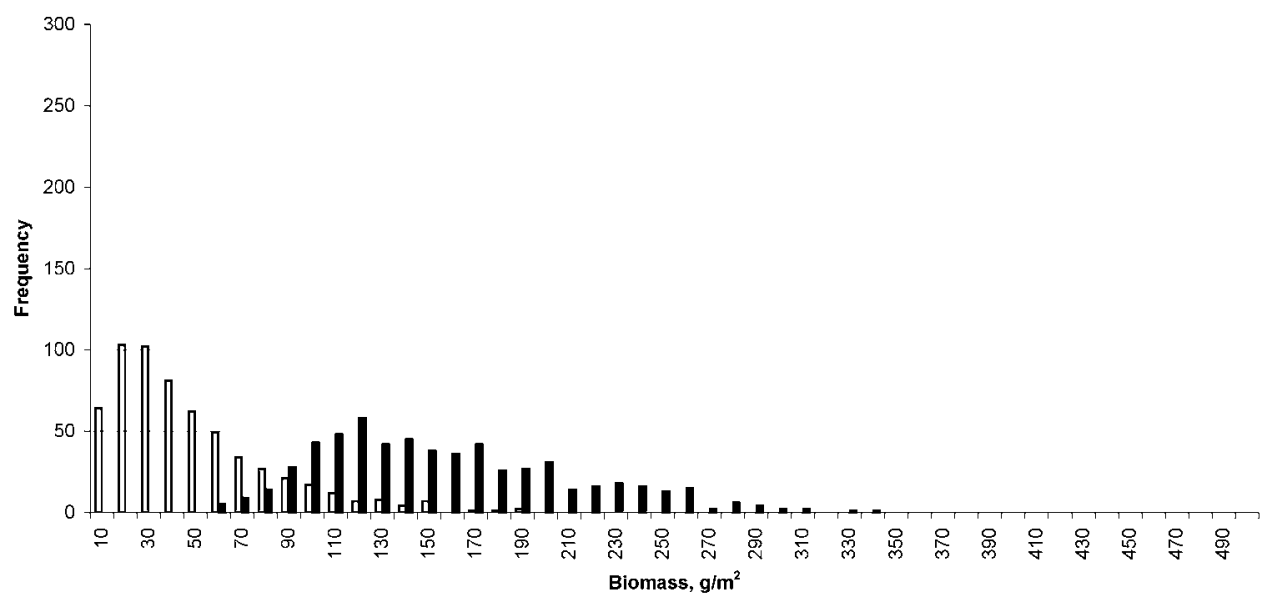

(b) Halsey, NE April through October biomass, $50 \% C_{3} 50 \% C_{4}$ species $1904-1934,75 \% C_{4}$ species 1935 1989, observed climate 1904-1934, 1934 climate 1935-1989

DAboveground Live Carbon Belowground Live Carbon

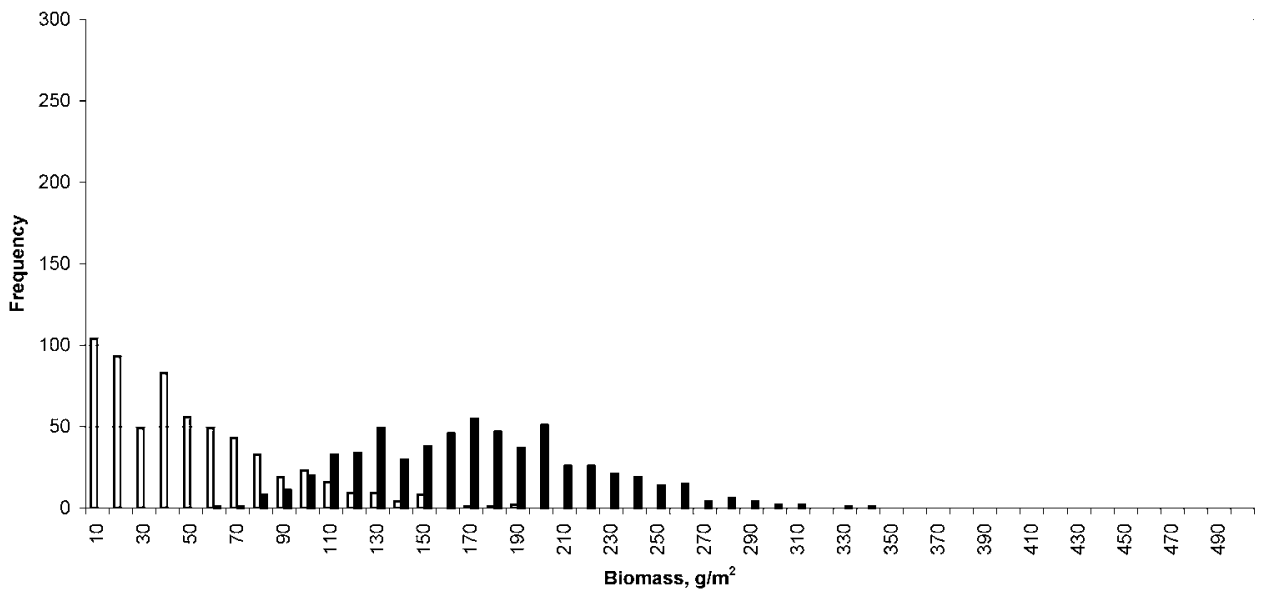

Figure 11. Frequency distribution plots of CENTURY aboveground and belowground live carbon model output for 1904-1989. (a) Experiment used observed data from 1904-1934 and 1935-1989 climate data rescaled to mean 1934 conditions for 1935-1989 and ecosystem shifts to 75 percent $\mathrm{C}_{3}$ plants after 1934. (b) Experiment used observed data from 1904-1934 and 1935-1989 climate data rescaled to mean 1934 conditions for 1935-1989 and ecosystem shifts to 75 percent $C_{4}$ plants after 1934. 
(a) Halsey, NE observed climate and mixed C3/C4 grassland 1903-1933, 1934 precipitation and $75 \%$ C3 $25 \%$ C4 plants $1934-1989$

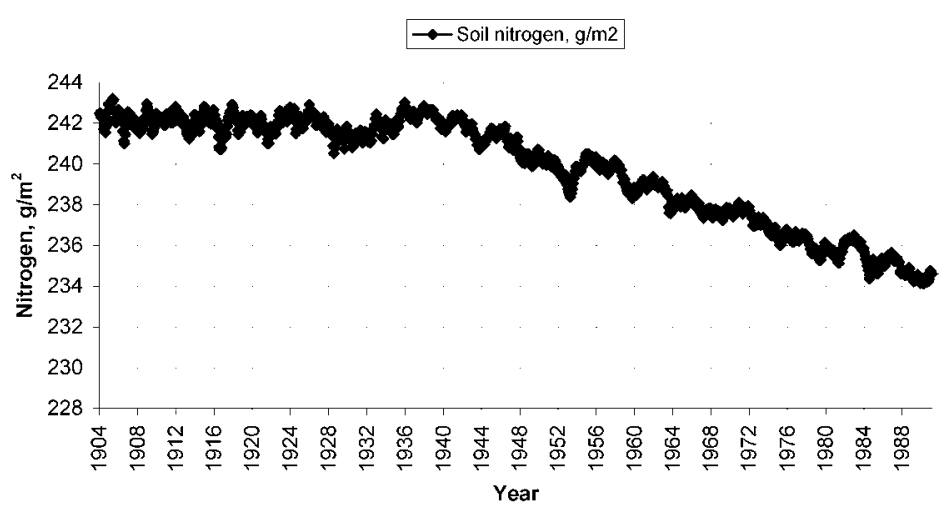

(b) Halsey, NE observed climate and mixed C3/C4 grassland 1903-1933, 1934 precipitation and $75 \%$ C4 25\% C3 plants $1934-1989$

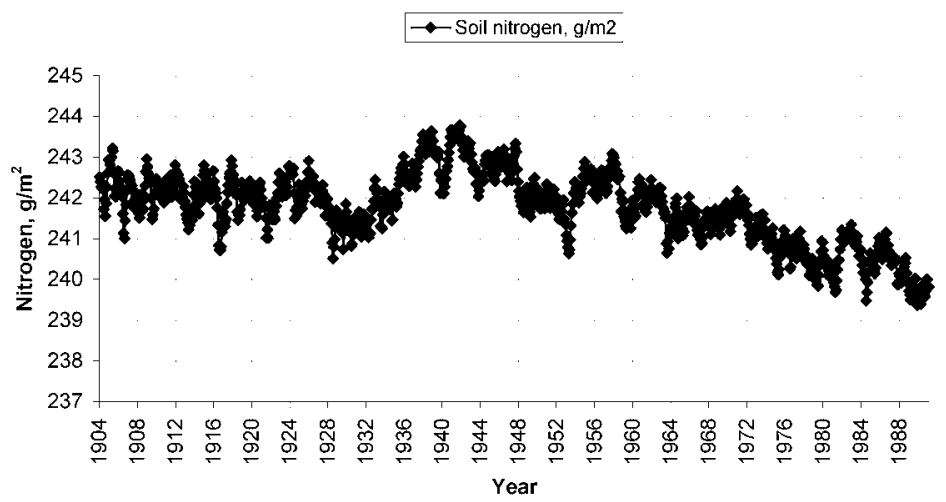

Figure 12. Soil nitrogen dynamics for (a) an ecosystem change to 75 percent $\mathrm{C} 3$ species after the 1934 drought and (b) an ecosystem change to 75 percent C4 species after 1934. More C3 than C4 species tends to cause soil nitrogen depletion while a $75 \% \mathrm{C} 4$ ecosystem maintains the original soil nitrogen balance.

species vs. the control (Table III). Aboveground live carbon is not normally distributed with all one plant functional type but belowground live carbon is (Figure 13b). The $\mathrm{p}$ values for 100 percent $\mathrm{C} 3$ species or 100 percent $\mathrm{C} 4$ species vs. the control are significant at 0.636 and 0.527 , respectively (Table III). However, belowground live carbon shifts to moderately higher amounts of biomass, with a difference of $37.32 \mathrm{~g} / \mathrm{m}^{2}$ from the extended 1934 drought experiment (Table II). A shift to only one plant functional type will impact belowground live carbon more than it will impact aboveground live carbon.

Soil nitrogen dynamics when the environment shifts to entirely one plant functional type differ from soil nitrogen dynamics when the environment has 75 percent of one plant functional type. When the ecosystem shifts to 100 percent $C_{3}$ species 
Halsey, NE April through October biomass frequencies, $100 \% \mathrm{C} 3$ species and $1 \mathrm{~mm}$ monthly January-April erosion after 1934

(a) $\square$ Aboveground Live Carbon Belowground Live Carbon

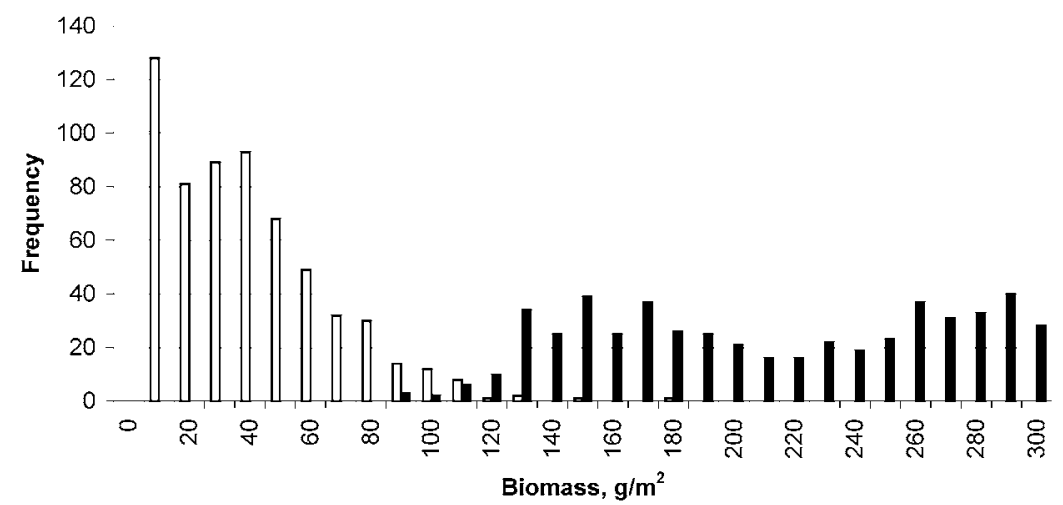

(b) Halsey, NE April through October biomass frequencies, 100\% C4 species and $1 \mathrm{~mm}$ monthly January - April erosion after 1934

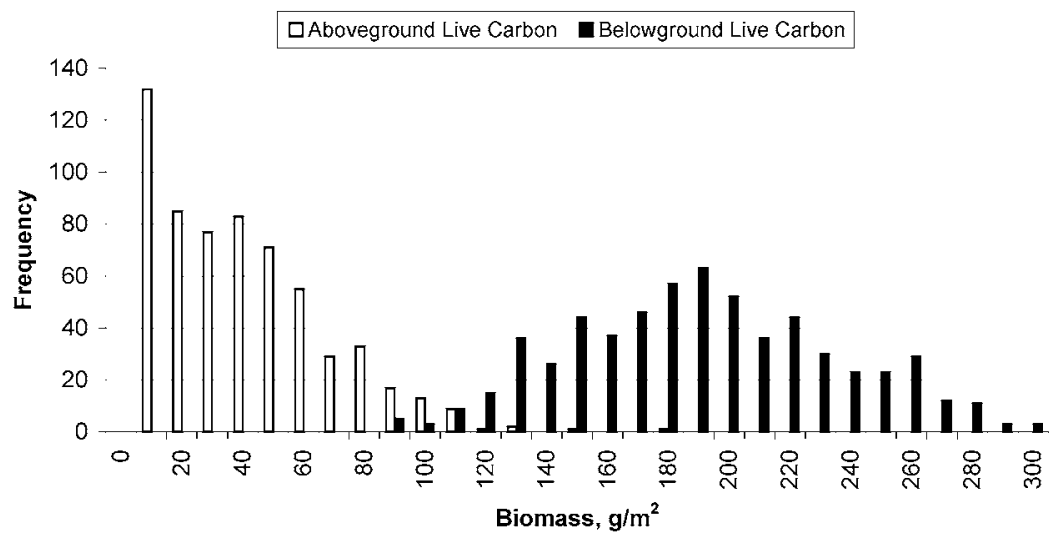

Figure 13. Frequency distribution plots of CENTURY aboveground and belowground live carbon model output for 1904-1989. (a) Experiment used observed data from 1904-1934 and 1935-1989 climate data rescaled to mean 1934 conditions for 1935-1989 and ecosystem shifts to 100 percent C3 plants after 1934. (b) Experiment used observed data from 1904-1934 and 1935-1989 climate data rescaled to mean 1934 conditions for 1935-1989 and ecosystem shifts to 100 percent C4 plants after 1934.

in response to drought, soil nitrogen decreases only slightly, by a maximum of $5 \mathrm{~g} / \mathrm{m}^{2}$ within 18 years, but then rebounds and varies about $240 \mathrm{~g} / \mathrm{m}^{2}$, only $2 \mathrm{~g} / \mathrm{m}^{2}$ less than its initial equilibrium value. When the model environment changes to 100 percent $\mathrm{C}_{4}$ species in 1934 , there is no initial change in soil nitrogen but after about 20 years there is a slight increase of no more than $2 \mathrm{~g} / \mathrm{m}^{2}$ (Figure 14b). A plant functional type shift to entirely $\mathrm{C}_{4}$ species does not appear to significantly affect the soil nitrogen equilibrium. 
(a) Halsey, NE observed climate and mixed C3/C4 grassland 1903-1933, 1934 precipitation and $75 \%$ C3 $25 \%$ C4 plants $1934-1989$

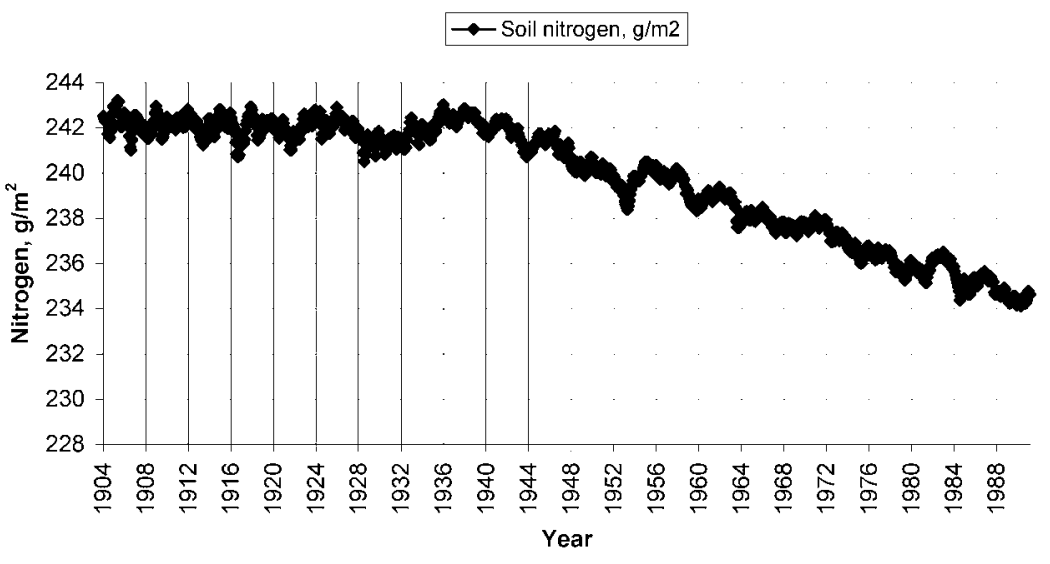

(b) Halsey, NE observed climate and mixed C3/C4 grassland 1903-1933, 1934 precipitation and $75 \%$ C4 25\% C3 plants $1934-1989$

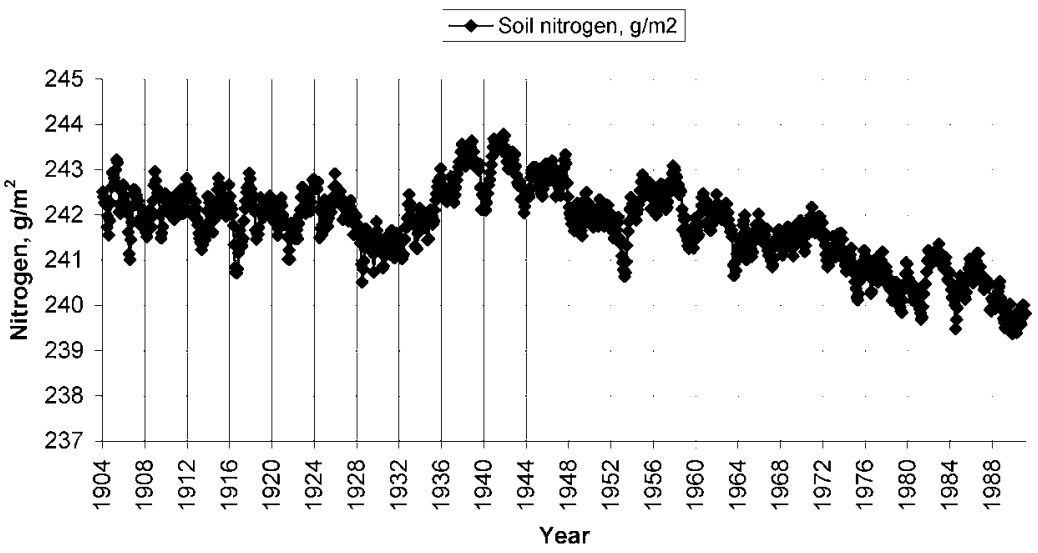

Figure 14. Soil nitrogen dynamics for (a) an ecosystem change to 75 percent $\mathrm{C} 3$ species after the 1934 drought and (b) an ecosystem change to 75 percent C4 species after 1934. More C3 than C4 species tend to cause soil nitrogen depletion while a 75 percent $\mathrm{C} 4$ ecosystem maintains the original soil nitrogen balance.

\section{Discussion}

CENTURY model output using observed twentieth century climate input shows a normal distribution and similar mean and median values for both aboveground and belowground plant components during the growing season, suggesting that the 1934-1940 drought was not sufficient to disrupt long-term vegetation abundance. Weaver (1950) confirms that after the drought ended in 1940, vegetation quickly repopulated barren soil. Species distribution during the 1930s drought had been 
altered, but the Nebraska grassland as a whole made a recovery within three years (Weaver, 1950; Weaver and Albertson, 1954), which is fairly rapid. Recent studies at Great Sand Dunes National Monument in Colorado have demonstrated that sand can quickly restabilize if vegetation density increases from 10 to 20 percent cover (Valdez, 1990).

Weaver and Albertson (1936) and Weaver (1943) observed that the Nebraska prairie consisted largely of little bluestem (Schizycharium scoparium), a $\mathrm{C}_{4}$ plant, prior to 1934. These species were replaced by western wheatgrass (Pascopyron smithii), a $\mathrm{C}_{3}$ plant, after this severe drought year (Weaver et al., 1935; Weaver, 1943). The 1934 drought was a summer drought and sufficient spring rainfall in 1935 allowed the $C_{3}$ wheatgrass to expand its range and possibly play a role in continued dune stability throughout the 1930s drought.

Hypothetical extension of the 1934 drought produced a thinning of plants in the model results. Vegetation was still present in some abundance even when the driest year of the 1930s drought is extended, suggesting that the Sand Hills vegetation community is physiologically adapted to lower moisture values, and can persist sufficiently to survive with reduced precipitation. The average aboveground biomass for the 56-year extended 1934 drought simulation was 69 percent of the average simulated in the control CENTURY run. Therefore, even an extension of climate severity equal to the Dust Bowl drought probably is not sufficient to cause sand dune mobilization. Examining extended drought is important because no dry spell lasting more than three years occurred during the 1930s, in contrast to earlier paleodroughts (Woodhouse and Overpeck, 1999). Although the 1930s are often perceived as having been consistently dry, in reality some years received adequate spring and summer rainfall. The years with sufficient precipitation provided moisture relief to the vegetation, and thus allowed it some opportunity to recover. It is therefore difficult to assess from observation alone the impact of drought lasting more than three years.

A major goal of this research is to determine the CENTURY-predicted vegetation abundance threshold at which dunes could remobilize. The key to the six experiments in which we sequentially reduced precipitation from ten percent to sixty percent is to determine what initial level of drought may be too severe to allow for any dune-stabilizing vegetation to thrive if arid conditions persist. Precipitation at 40 percent of 1934 values reduced aboveground biomass amounts to predominantly less than thirty grams per square meter. Therefore, the 40 percent precipitation simulation produced aboveground biomass values at 42 percent or less of the control average aboveground biomass value of $68.2 \mathrm{~g} / \mathrm{m}^{2}$ (Table II). When precipitation is simulated at 50 percent of 1934 values, aboveground biomass values are predominantly less than $20 \mathrm{~g} / \mathrm{m}^{2}$. At this point the majority of land cover will have only thirty percent or less of the control average aboveground biomass.

The belowground biomass values at 60 percent moisture depletion are still greater than the aboveground values in the observed climate control run, however. We know that the dunes are stable with the current amounts of vegetation on them; 
we are not yet certain how much of this stability is attributable to aboveground plant portions. If belowground biomass has a significant role in stabilizing the dunes, it is possible that even if precipitation levels were to decrease to sixty percent of 1934 levels, enough vegetation would remain to hold the sand in place. The model results show that belowground live carbon is slower to respond to drought; this slow response is evident because belowground live carbon does not lose its normal distribution as quickly as aboveground live carbon. Therefore we may postulate that rooting systems may be an important contributing factor to dune stability.

Vegetation health and abundance are the keys to dune stability. It is possible that dunes may reactivate even with small, sparse vegetation communities still on them, and Valdez (1990) has observed that 10 percent ground cover appears to be sufficient to prevent sand movement. Rooting depth of short-grass species such as little bluestem becomes shallower during drought (Weaver and Albertson, 1954). Decreased root depth means that many prairie species are less able to take advantage of underground water and thus depend more on precipitation. If precipitation is lacking for any extended period of time, it will most likely cause the loss of these short grasses. Before 1934 some short grass species comprised up to 90 percent of Nebraska rangeland; the drought of the 1930s reduced this cover to between 1 percent and 20 percent (Weaver and Albertson, 1954; Weaver, 1965). Little bluestem (Schizycharium scoparium), a short-grass species, suffered losses of 95 percent in some parts of Nebraska (Weaver, 1943). Little bluestem's dependence on precipitation, and its shallow roots, made the species more likely to succumb to lack of rainfall than deeper-rooted species that can utilize underground water resources. Despite heavy losses for the short grasses during the Dust Bowl years, species with deep rooting systems, particularly forbs, survived and some actually increased their cover. These forbs included blazing star (Liatris punctata), aster (Aster multiflorus), goldenrods (Solidago sp.), prairie rose (Rosa arkansana), false boneset (Kuhnia flutinosa), and longbract wild indigo (Baptisia leucophaea) (Weaver et al., 1935). Many forbs have large taproots that can penetrate the soil more than three meters (Weaver and Albertson, 1954). Forb cover on the plains was not dense, but these xeric plants did expand their range of coverage and served to stabilize the soil somewhat. Stability of dunes in any given location may depend on the ability of the plant community to adapt to the current moisture regime.

Grazing and fire are natural occurrences on the High Plains (Parton et al., 1993; Ojima et al., 1994). It follows that the vegetation would be adapted to these regimes under normal, non-drought conditions. These CENTURY modeling results confirm this adaptation because aboveground and belowground vegetation both retain their normal distribution curves when subjected to regular fire or grazing events and because net productivity changes little or not at all. During a drought, however, addition of either fire or grazing to an already-stressed vegetation community has an extremely detrimental effect, equivalent to decreasing precipitation abundance by sixty percent. This result implies that extreme caution must be used in allowing potential grassland stressors, such as fire or grazing, during a drought to avoid 
serious damage to the ecosystem. It may therefore be inferred that grazing by wild animals may have exacerbated the effects of droughts prior to the 20th century. Fire also may have contributed to greater drought impacts before European settlement but paleoecological data suggest paleodroughts may have acted to reduce fuel and therefore fire frequency in the past (Grimm and Clark, 1998).

Vegetation communities are not static; they consist of many individual species that will adapt independently to shifts in climate. The CENTURY model cannot simulate individual species, but it can simulate responses of $\mathrm{C}_{3}$ and $\mathrm{C}_{4}$ photosynthetic pathway plants. A change in seasonality of moisture availability could serve to favor one type of plant over the other. $\mathrm{C}_{3}$ plants will take advantage of spring rains while $\mathrm{C}_{4}$ plants require moisture during the summer. If a summer drought were to occur, the $\mathrm{C}_{4}$ plant species would almost certainly be damaged but $\mathrm{C}_{3}$ plants would not necessarily be adversely affected; likewise a spring drought could cause heavy losses in the $\mathrm{C}_{3}$ community but adequate summer rains would not harm the $\mathrm{C}_{4}$ plants. Therefore it seems that droughts spanning both spring and summer would be required to reduce vegetation cover sufficiently to reactivate the dunes.

The CENTURY model experiments reveal a dramatic decrease in aboveground live carbon when either $\mathrm{C}_{3}$ or $\mathrm{C}_{4}$ abundances are increased to 75 percent from 50 percent after 1934 and 1934 drought climate conditions are perpetuated. Increasing amounts of $\mathrm{C}_{3}$ or $\mathrm{C}_{4}$ plants to 100 percent after 1934 while maintaining drought conditions also has a large effect; aboveground live carbon decreases significantly relative to the prolonged drought experiment while belowground live carbon increases. This belowground live carbon increase could reflect reduced species competition and proliferation of rooting systems. Many prairie grass species have extensive root and rhizome systems. Blowout grass (Redfieldia flexuosa), for example, is the first to colonize bare areas and has no initial competition from other plant species (Weaver, 1965). Blowout grass has extensive rhizomes that radiate out as far as 22 meters (Weaver, 1965), and these underground plant parts would be reflected in the CENTURY model's simulation of belowground live carbon.

A change to predominantly $\mathrm{C}_{3}$ plants would be likely to occur if precipitation is abundant in spring and if summer rainfall is greatly reduced from the present-day (Epstein, 1999). A spring drought might be extremely harmful to a 75 percent $C_{3}$ plant community and make it highly susceptible to sand activation from rapid plant deaths. Decreased root and shoot abundances mean there would be less live carbon available for sand stabilization but we do not know if a shift to 75 percent $C_{3}$ plants will reduce overall biomass sufficiently for sand activation to occur.

Decreases in aboveground carbon abundance when either $\mathrm{C}_{3}$ or $\mathrm{C}_{4}$ species become 100 percent of the vegetation could represent plants increasing their root volumes at the expense of shoots. During the Dust Bowl drought, xeric forbs with large taproots persisted but aboveground they were dwarfed (Weaver and Albertson, 1954). Likewise, other species seemed absent but dormant remnants lay underground (Weaver and Albertson, 1954). It would make sense for plants subjected to drought to concentrate their reserves of carbon in their roots, which 
are responsible for water uptake. Plants which can root a little bit more deeply have a better chance at reaching underground water reserves than plants that have large aboveground parts and small roots.

If spring rainfalls are adequate and the summers are dry, $\mathrm{C}_{3}$ plants will predominate because they begin growing and reach their peak productivity in spring to early summer (Epstein et al., 1999). Currently, the precipitation regime on the High Plains, and that which we used in the CENTURY model experiments, has peak precipitation in late spring. Thus the environment is favorable for $\mathrm{C}_{3}$ plant growth. $\mathrm{C}_{4}$ plants tend to peak in mid-summer unless there is a drought; during a summer drought $\mathrm{C}_{4}$ plants may become dormant or die. If summer precipitation is sufficient but spring rains are lacking, $\mathrm{C}_{4}$ plants may flourish and move into the niches left by $\mathrm{C}_{3}$ plants that may not survive a spring drought (Epstein et al., 1999). It would seem then, that the mix of two plant functional types acts as a buffer to seasonal droughts, and an increase in $\mathrm{C}_{4}$ plants would not damage the ecosystem due to the fact that summers currently do not receive large amounts of rainfall. Symstad and Tilman (2001) have noted, however, in field studies that the vegetation plots most resistant to drought are those containing only $\mathrm{C}_{3}$ or $\mathrm{C}_{4}$ species. Therefore it is possible that an ecosystem's best defense against drought would be to at least temporarily shift to a vegetation community containing only one plant functional type.

Simulated belowground live carbon in an entirely $\mathrm{C}_{4}$ plant community may not increase as much as in an entirely $\mathrm{C}_{3}$ plant community because $\mathrm{C}_{4}$ plants are already more deeply and/or extensively-rooted than $\mathrm{C}_{3}$ species (Weaver, 1956), and thus would not spread as much in the absence of competition. Symstad and Tilman (2001) also found that $C_{3}$ species have extensive rhizome systems that will quickly colonize bare space, thereby rapidly increasing the amount of belowground live carbon present in the ecosystem. If the plant community were to shift to entirely $\mathrm{C}_{3}$ or $\mathrm{C}_{4}$ plants, the model results indicate that dune mobilization would be unlikely due to the increase in soil-stabilizing underground plant parts.

Weaver (1954) noted that the High Plains drought of 1934 greatly reduced the amounts of little bluestem (Schizycharium scoparius), a $\mathrm{C}_{4}$ species, in Nebraska, where it had dominated the landscape. In the spring of 1935, western wheatgrass (Agropyron smithii), a $\mathrm{C}_{3}$ species, invaded the niches previously occupied by little bluestem, and remained the dominant species until the end of the drought in 1940, when little bluestem started to recover. Recent studies (Tilman, 1987; Symstad and Tilman, 2001) have reproduced this effect and demonstrated that soil nitrogen is an important factor impacting the dynamics of these species. Symstad and Tilman (2001) have also found that the ability to colonize bare space and make use of available nutrients differs between $\mathrm{C}_{3}$ and $\mathrm{C}_{4}$ species, and can affect how an area responds to drought or other disturbances.

Initiation of erosion in the CENTURY model, with or without drought, causes an initial peak in soil nitrogen (Figure 7). In the CENTURY model, more nitrogen is available from plant death and it leaches into the lowest layer of the soil, causing 
the nitrogen peak (C. Keough, personal communication), but reflects what has been observed in the field (Tilman, 1987). Thus there is initially a nitrogen-enriched soil. Tilman (1987) also discovered that Agropyron sp. grows preferentially in high-nitrogen environments whereas Schizycharium scoparius is more abundant in moderate to low-nitrogen soils. Further, Agropyron $s p$. is an early-succession species that tends to colonize disturbed regions whereas $S$. scoparius is a latersuccessional species that grows in already-established vegetation communities (Tilman, 1987). This combination of factors could partly explain why Weaver and Albertson (1936) observed western wheatgrass (Agropyron smithii) in 1935 aggressively colonizing areas left bare where little bluestem had succumbed to the drought of the previous summer. The area may have been both disturbed and probably nitrogen-enriched, creating an ideal environment for the growth of western wheatgrass. However, the soil horizons in dune fields are extremely thin, and the amounts of nitrogen they may have contained might not have been significant enough to account for a species shift. Alternatively, High Plains grasslands species are extremely sensitive to even subtle shifts in nitrogen amounts.

It appears that erosion of only $0.25 \mathrm{~mm}$ monthly, or $1 \mathrm{~mm}$ per year during the spring is the equivalent of a drought with $20 \%$ less precipitation than the High Plains received in 1934. The implication of this result is that the United States dune fields could become quickly and highly susceptible to remobilization if minimal erosion and severe drought combine in the future. However, we used CENTURY version 4 for our simulations. Version 5 has recently become available, with a more extensive erosion and deposition routine. It is possible that our results would have varied had we had access to the newer version of CENTURY during our model simulations. However, our results do seem to be accurate because the dunes were on the verge of mobilizing in the 1930s even though they did not become fully active. It therefore makes sense that even just slightly more severe conditions could cause the dunes to cross the threshold between almost and fully mobilized.

Schizycarium scoparius (little bluestem) actually declines in abundance along an increasing nitrogen gradient (Tilman, 1987). In the event of a drought on the High Plains, the resulting plant deaths and soil nitrogen enrichment would make conditions less than optimal for little bluestem to quickly re-establish itself. Therefore, species such as the early-successional western wheatgrass (Agropyron smithii), although seen as weeds, may play a critical role in helping to at least temporarily stabilize the soil in the event of a drought severe enough to destroy the established vegetation community. Soil stabilization by wheatgrass may be what occurred during the Dust Bowl of the 1930s, and part of the reason we did not see widespread sand dune remobilization as a result of the drought. Tilman (1987) notes that Agropyron sp. is present mostly in recently disturbed fields, and that its abundance declines in areas that were disturbed more than 10 years ago. The colonization pattern of Agropyron sp. carries several implications regarding the Dust Bowl drought. 
The Dust Bowl drought in Nebraska lasted roughly 6 years, from 1934 to 1940, although 1935 was technically not a drought year. Therefore, the drought did not last longer than the average lifespan for Agropyron smithii growing in disturbed fields, and this species was easily able to take advantage of the barren spaces and increased nitrogen abundance in the soil. When the rains returned in 1940, it is likely that the soils were stable enough for little bluestem to begin to grow again, and wheatgrass had probably depleted the soil nitrogen sufficiently (Tilman, 1987) to allow for growth of little bluestem again. Therefore, for droughts lasting less than 10 years, species interactions and soil nitrogen dynamics may create an environment where vegetation is able to prevent widespread soil mobilization. If a drought lasts more than 10 years, there is greater potential for significant vegetation depletion and reactivation of sand dunes.

CENTURY is itself a 1-D model and in this study we are attempting to model highly 3-D landscapes, a situation that must be taken into consideration in light of our results. Nutrient cycling is not going to be uniform across every portion of the Nebraska Sandhills for a variety of reasons. The following is an explicit list of some of the problems encountered when using CENTURY, a 1-D model, to simulate effects on the three-dimensional dune fields of Nebraska.

- CENTURY simulations that use weather data files that generate model output assuming the landscape is uniformly reflected by the mean monthly maximum temperature, minimum temperature, and precipitation values in the weather file.

- A CIR or NDVI image of Nebraska shows that much of the surface is characterized by dune fields, hummocks, pocket lakes, rivers, and farmland, all of which will be affected differently by climate and support different types of vegetation.

- Even close examination of sand dune fields alone reveals that the fields are topographically diverse, with ridge tops, slopes, and interdune swales, all of which have their own vegetation and microclimate.

- Interdune swales are moister than dune slopes or ridges because runoff accumulates between the dunes, creating moister soil and an environment in which more or different plant species can grow than on the slopes or ridge tops.

- CENTURY runs require specification of one vegetation type or combination of types, e.g., $\mathrm{C}_{3}$ grassland, mixed $\mathrm{C}_{3} / \mathrm{C}_{4}$ grassland. From the specified vegetation type, Century determines how much lignin and metabolic carbon and nitrogen are present in the ecosystem for cycling. CENTURY does not account for the fact that the cooler, moister swales may produce a microecosystem that is not representative of a $\mathrm{C}_{3} / \mathrm{C}_{4}$ grassland, for example. The swales may support some woody vegetation, which has a higher lignin content than grasses, and thus during a drought the woody plants will contribute less $\mathrm{C}$ and $\mathrm{N}$ to the soil via senescence. 
- Erosion in CENTURY version 4.0 occurs within the top $20 \mathrm{~cm}$ of soil, but affects nutrient cycling processes at all soil layers. Nutrients in the lower horizon pools cycle upwards to replace any $\mathrm{C}$ and $\mathrm{N}$ removed by the erosion process. Specifying erosion in the CENTURY model implies that erosion is occurring uniformly across the landscape, whereas in reality it is more likely affecting a much smaller scale region. Therefore, within CENTURY, $\mathrm{C}$ and $\mathrm{N}$ from the topsoil is being removed for the whole area and replaced with lower horizon $\mathrm{C}$ and $\mathrm{N}$, which will vary depending on initial $\mathrm{C}$ and $\mathrm{N}$ values in the lower soil layers. In reality, nutrient cycling and its effect on surface vegetation may not be affected by this erosion activity.

- CENTURY would have difficulty accurately simulating nitrogen volatization and cycling across the span of these 3-D landscapes because these nitrogen processes are dependent upon climate variables, and the microclimate differences between dune ridges are sufficiently different to differently impact nitrogen. Decomposition of $\mathrm{N}$ in the active, passive, and slow nitrogen pools results in net mineralization of $\mathrm{N}$, which then becomes available for volatization as $\mathrm{NO}_{3}$. However, decomposition of structural residue, or plant material with a high lignin content, immobilizes $\mathrm{N}$, making less available for release to the atmosphere. Since swales may support more vegetation, therefore more nitrogen is present in living and decomposing plant matter, making more $\mathrm{N}$ available for cycling and volatization. Losses of $\mathrm{N}$ are from leaching of $\mathrm{NO}_{3}$ and are related to both soil texture and to the amount of water moving through the vertical soil profile. Swales will tend to have finer soils of finer texture than the coarse-textured dune ridges, and less $\mathrm{N}$ will be lost from swales than from ridges. Also swales will have more water moving through them because of runoff from the surrounding dunes, thereby increasing $\mathrm{N}$ content of the swales.

- Although there is a newer CENTURY version with an improved erosion routine available now, future versions of CENTURY might improve further upon the erosion parameterization by enhancing the link between wind strength and subsequent litter removal/nutrients available for leaching back into the soil.

- CENTURY currently only allows for a tree removal parameterization, specifying how much of the deceased tree nutrients are cycled back into the soil; currently there is significant wind on the High Plains dune fields to remove much of this litter layer, hence CENTURY may be overestimating how much tree nutrients are available for recycling.

\section{Conclusions}

CENTURY model results suggest that if the mid-1930s drought was extended for decades, aboveground vegetation might decrease but not enough to allow for widespread sand dune remobilization. Observations show that the low precipitation 
amounts received by the High Plains in the 1930s did have detrimental impacts on the native vegetation populations, but enough plants were able to persist that long-term vegetation abundance was not altered. Incremental increases in the intensity of the 1934 drought reduced aboveground and belowground biomass, but it is the introduction of erosion into the ecosystem model that provides a more realistic view of vegetation dynamics during a drought. Erosion removes not only soil, but nutrients, including the important nutrient nitrogen, thereby creating an environment in which plants are less likely to thrive.

Vegetation health and abundance, nitrogen availability, and fire and grazing impacts are key factors for determining dune mobilization potentials. Our simulations of annual low-intensity grazing and of a three-year fire regime reveal that there is no change in net productivity relative to the control. The additive effects of fire or grazing combined with the 'mild' drought are more significant, increasing the impact of drought on both aboveground and belowground biomass. Erosion in conjunction with fire or grazing and mild drought is more detrimental to the ecosystem than fire or grazing alone coupled with drought, again reinforcing the idea that even small amounts of soil removal can cause depletion of both aboveground and belowground carbon.

The impacts of changes in the overall Sand Hills ecosystem in response to drought are also important. The two different plant functional types $\left(\mathrm{C}_{3}\right.$ and $\left.\mathrm{C}_{4}\right)$ are adapted to different seasonalities of precipitation. The model results suggest that if drought causes one plant functional type to increase at the expense of the other, overall ecosystem biomass will decrease. However, a composition shift to either 75 percent $\mathrm{C}_{3}$ or 75 percent $\mathrm{C}_{4}$ plants is statistically comparable to a 30 percent decrease in 1934 precipitation. Therefore it is not likely that if the community becomes either 75 percent $\mathrm{C}_{3}$ or 75 percent $\mathrm{C}_{4}$ plants that dunes will remobilize, but the ecosystem could be left more vulnerable. Addition of erosion to either of these shifting ecosystems disrupts the normal distribution of both aboveground and belowground live carbon, but especially aboveground live carbon.

CENTURY model results indicate that altering the vegetation community to 100 percent $\mathrm{C}_{3}$ or $\mathrm{C}_{4}$ species will have a noticeable effect. Absence of competition can allow for proliferation of one plant functional type. If either $\mathrm{C}_{3}$ or $\mathrm{C}_{4}$ plants were to exclusively dominate the High Plains prairie community, CENTURY simulates an increase in belowground root and rhizome systems, and a decrease in plant shoots. Under the current seasonality of precipitation on the High Plains, model results suggest that $\mathrm{C}_{3}$ plants could benefit from an exclusively $\mathrm{C}_{3}$ community more so than $\mathrm{C}_{4}$ plants would benefit from an entirely $\mathrm{C}_{4}$ community. However, addition of erosion changes this scenario. The CENTURY simulation where the soil is eroded and the ecosystem becomes entirely $\mathrm{C} 4$ species shows that belowground live carbon frequencies maintain a normal distribution, suggesting that the ecosystem is stable and not undergoing change. Although aboveground live carbon seems to be shifting to lower values, the stability of the belowground carbon could 
eventually facilitate stabilization of the community if it is able to maintain this normal distribution, hence, stability.

Nitrogen cycling can also affect Sand Hills vegetation communities. A prescribed erosion event in CENTURY removes soil and nutrients available to the vegetation. Removal of nitrogen from the soil will affect the vegetation community, since nitrogen is a controlling factor over the composition and health of grassland ecosystems. Nitrogen always decreases with erosion, but its response varies for other environmental stressors. In drought simulations, soil nitrogen decreases over time. However, soil nitrogen actually increases slightly if the vegetation community is manipulated to become entirely $\mathrm{C}_{4}$ species. The soil nitrogen increase may be attributed to the fact that many $\mathrm{C}_{4}$ grasses, such as little bluestem, grow in clumps and tend to prefer lower-nitrogen environments. Therefore, these plants do not utilize large amounts of nitrogen and it remains in the soil.

Seasonality of precipitation will affect both $\mathrm{C}_{3}$ and $\mathrm{C}_{4}$ plants. A spring drought would have the potential to harm the $\mathrm{C}_{3}$ plant community while a summer drought would be most detrimental to $\mathrm{C}_{4}$ plants. In either case, one plant functional type would be able to survive and remain to stabilize the soil. The mixed grassland community has a buffer that allows it to withstand drought in one season, but drought spanning through both spring and summer could possibly reduce vegetation cover to 10 percent or less, which, according to Valdez (1990) would allow for sand dune remobilization.

\section{Acknowledgements}

The authors would like to thank Dennis Ojima and Bill Parton for helpful discussions that improved our modeling approach. Robin Kelly and Cindy Keough of the Natural Resource Ecology Laboratory (NREL) at Colorado State University provided invaluable assistance with the CENTURY model. Gilbert Compo of the Climate Data Center at NOAA assisted with questions about statistical concerns. Computer support for this project was provided by the Center for the Study of Earth from Space at the University of Colorado. Support for this research came from the NASA Land Cover Land Use Change (LCLUC) program and the NOAA Paleoclimatology program.

\section{References}

Ahlbrandt, T. S., Swinehart, J., and Maroney, D. G.: 1983, 'The Dynamic Holocene Dune Fields of the Great Plains and Rocky Mountain Basins, U.S.A.', in Brookfield, M. E. and Ahlbrandt, T. S. (eds.), Eolian Sediments and Processes, Elsevier, Amsterdam, pp. 379-406.

Alward, R. D., Detling, J. K., and Milchunas, D. G.: 1999, 'Grassland Vegetation Changes and Nocturnal Global Warming', Science 283, 229-231. 
Bartlein, P. J., Anderson, K. H., Anderson, P. M., Edwards, M. E., Mock, C. J., Thompson, R. S., Webb, R. S., Webb III, T., and Whitlock, C.: 1998, 'Paleoclimate Simulations for North America over the Past 21,000 Years; Features of the Simulated Climate and Comparisons', Quat. Sci. Rev. 17, 549-585.

Bolker, B. M., Pacala, S. W., and Parton, W. J.: 1998, 'Linear Analysis of Soil Decomposition, Insights from the CENTURY Model', Ecological Applications, 8, 425-439.

Causton, D. R. and Venus, J. C.: 1981, The Biometry of Plant Growth, Edward Arnold, London.

Earth Info: 2000, NOAA Climatic Data Center Summary of the Day, EarthInfo, Inc., Boulder, CO.

Epstein, H. E., Burke, I. C., and Lauenroth, W. K.: 1999, 'Response of the Shortgrass Steppe to Changes in Rainfall Seasonality', Ecosystems 2, 139-150.

Forman, S. L., Goetz, A. F. H., and Yuhas, R.: 1992, 'Large-Scale Stabilized Dunes on the High Plains of Colorado, Understanding the Landscape Response to Holocene Climates with the Aid of Images from Space', Geology 20, 145-148.

Forman, S. L., Oglesby, R., Markgraf, V., and Stafford, T.: 1995, 'Paleoclimatic Significance of Later Quaternary Eolian Deposition on the Piedmont and High Plains, Central United States', Global Plan. Change 11, 35-55.

Grimm, E. C. and Clark, J. S.: 1998, 'Holocene Vegetation and Climate Change in the Northern Great Plains; Evidence from Pollen and Charcoal Studies', Abstracts with Programs, Geological Society of America, Boulder, CO.

Hobbs, N. T., Schimel, D. S., Owensby, C. E., and Ojima, D. S.: 1991, 'Fire and Grazing in the Tallgrass Prairie, Contingent Effects on Nitrogen Budgets', Ecology 72, 1374-1382.

Holliday, V. T.: 1989, 'Middle Holocene Drought on the Southern High Plains', Quatern. Res. 31, 74-82.

Holliday, V. T.: 1991, 'The Geologic Record of Wind Erosion, Eolian Deposition, and Aridity on the Southern High Plains', Great Plains Research 1, 6-25.

Johnson, E. and Holliday, V. T.: 1989, 'Lubbock Lake, Late Quaternary Cultural and Environmental Change on the Southern High Plains, U.S.A.', J. Quatern. Sci. 4, 145-165.

Jorgenson, D. W.: 1992, 'Use of Soils to Differentiate Dune Age and to Document Spatial Variation in Eolian Activity, Northeast Colorado, U.S.A.', J. Arid Environments 23, 19-36.

Kutzbach, J., Gallimore, R., Harrison, S., Behling, P., Selin, R., and Laarif, F.: 1998, 'Climate and Biome Simulations for the Past 21,000 Years', Quat. Sci. Rev. 17, 473-506.

Laird, K. R., Fritz, S. C., Grimm, E. C., and Mueller, P. G.: 1996, 'Century-Scale Paleoclimatic Reconstruction from Moon Lake, a Closed-Basin Lake in the Northern Great Plains', Limnol. Oceanogr. 41, 890-902.

Loope, D., Swinehart, J., and Mason, J.: 1995, 'Dune-Dammed Paleovalleys of the Nebraska Sand Hills, Intrinsic vs. Climatic Controls on the Accumulation of Lake and Marsh Sediments', GSA Bulletin 107, 396-406.

Madole, R. F.: 1995, 'Spatial and Temporal Patterns of Late Quaternary Eolian Deposition, Eastern Colorado, U.S.A.', Quat. Sci. Rev. 14, 155-177.

Mock, C. J.: 1991, 'Drought and Precipitation Fluctuations in the Great Plains during the Late Nineteenth Century', Great Plains Research 1, 26-57.

Muhs, D. R.: 1998, 'Activation of Great Plains Dune Sand during the 1930s Drought', Geological Society of America 1998 Annual Meeting Abstracts with Programs, Geological Society of America, Boulder, CO.

Muhs, D. R. and Holliday, V. T.: 1995, 'Evidence of Active Dune Sand on the Great Plains in the 19th Century from Accounts of Early Explorers', Quatern. Res. 43, 198-208.

Muhs, D. R. and Maat, P. B.: 1993, 'The Potential Response of Eolian Sands to Greenhouse Warming and Precipitation Reduction on the Great Plains of the U.S.A.', J. Arid Environments 25, 351361. 
Muhs, D. R., Stafford, T. W., Cowherd, S. D., Mahan, S. A., Kihl, R., Maat, P.B., Bush, C. A., and Nehring, J.: 1996, 'Origin of the Late Quaternary Dune Fields of Northeastern Colorado', Geomorphology 17, 129-149.

Muhs, D. R., Stafford, T. W., Swinehart, J. B., Cowherd, S. D., Mahan, S. A., Bush, C. A., Madole, R. F., and Maat, P. B.: 1997, 'Late Holocene Eolian Aactivity in the Mineralogically Mature Nebraska Sand Hills', Quatern. Res. 48, 162-176.

Ojima, D. S., Schimel., D. S., Parton, W. J., and Owensby, C. E.: 1994, 'Long- and Short-Term Effects of Fire on Nitrogen Cycling in Tallgrass Prairie', Biogeochemistry 24, 67-84.

Overpeck, J. T.: 1996, 'Warm Climate Surprises', Science 271, 1820-1821.

Parton, W. J., Ojima, D. S., and Schimel, D. S.: 1994, 'Environmental Change in Grasslands, Assessment Using Models', Clim. Change 28, 111-141.

Parton, W. J., Schimel, D. S., Cole, C. V., and Ojima, D. S.: 1987, 'Analysis of Factors Controlling Soil Organic Matter Levels in Great Plains Grasslands', Soil Science of America Journal 51, 1173-1179.

Parton, W. J., Scurlock, J. M. O., Ojima, D. S., Gilmanov, T. G., Scholes, R. J., Schimel, D. S., Kirchner, T., Menaut, H.-C., Seastedt, T., Garcia Moya, E., Kamnalrut, A., and Kinyamario, J. L.: 1993, 'Observations and Modeling of Biomass and Soil Organic Matter Dynamics for the Grassland Biome Worldwide', Global Biogeochem. Cycles 7, 785-809.

Parton, W. J., Stewart, J. W. B., and Cole, C. V.: 1988, 'Dynamics of C, N, P and S in Grassland Soils, a Model', Biogeochemistry 5, 109-131.

Paruelo, J. M. and Lauenroth, W. K.: 1996, 'Relative Abundance of Plant Functional Types in Grasslands and Shrublands of North America', Ecol. Appl. 6, 1212-1224.

Pye, K., Winspear, N. R., and Zhou, L.P: 1995, 'Thermoluminescence Ages of Loess and Associated Sediments in Central Nebraska, U.S.A.', Palaeogeogr., Palaeoclimatol., Palaeoecol. 118, 73-87.

Qin, B., Harrison, S. P., and Kutzbach, J. E.: 1998, 'Evaluation of Modelled Regional Water Balance Using Lake Status Data, a Comparison of 6 ka Simulations with the NCAR CCM', Quatern. Sci. Rev. 17, 535-548.

Ryan, K.C.: 1991, 'Vegetation and Wildland Fire, Implications of Global Climate Change', Environment International 17, 169-178.

Schimel, D. S., Parton, W. J., Kittel, T. G. F., Ojima, D. S., and Cole, C. V.: 1990, 'Grassland Biogeochemistry, Links to Atmospheric Processes', Clim. Change 17, 13-25.

Shaw, G. and Wheeler, D.: 1985, Statistical Techniques in Geographical Analysis, John Wiley and Sons, New York.

Stokes, S. and Swinehart, J.: 1997, 'Middle- and Late-Holocene Dune Reactivation in the Nebraska Sand Hills, U.S.A.', The Holocene 7, 263-272.

Stubbendieck, J., Nichols, J. T., and Roberts, K. K.: 1985, Nebraska Range and Pasture Grasses, Nebraska Cooperative Extension Service, Lincoln, NE.

Symstad, A. J. and Tilman, D.: 2001, 'Diversity Loss, Recruitment Limitation, and Ecosystem Functioning: Lessons Learned from a Removal Experiment', Oikos 92, 424-435.

Tilman, D.: 1987, 'Secondary Succession and the Pattern of Plant Dominance along Experimental Nitrogen Gradients', Ecol. Monogr. 57, 189-214.

United States Department of Agriculture: 1994, State Soil Geographic (STATSGO) Database, USDA, Washington, D.C.

Vance, R. E., Beaudoin, A. B., and Luckman, B. H.: 1995, 'The Palaeoecological Record of 6 ka BP Climate in the Canadian Prairie Provinces', Geographie Physique et Quaternaire 49, 81-98.

Vance, R. E., Last, W. M., and Smith, A. J.: 1997, 'Hydrologic and Climatic Implications of a Multidisciplinary Study of Late Holocene Sediment from Kenosee Lake, Southeastern Saskatchewan, Canada', J. Paleolim. 18, 365-393.

Vance, R. E., Mathewes, R. W., and Clague, J. J.: 1992, '7000 Year Record of Lake-Level Change on the Northern Great Plains; a High-Resolution Proxy of Past Climate', Geology 20, 879-882. 
Weaver, J. E.: 1943, 'Replacement of True Prairie by Mixed Prairie in Eastern Nebraska and Kansas', Ecology 24, 421-434.

Weaver, J. E.: 1954, North American Prairie, Johnsen Publishing Company, Lincoln, NE.

Weaver, J. E.: 1965, Native Vegetation of Nebraska, University of Nebraska Press, Lincoln, NE.

Weaver, J. E. and Albertson, F. W.: 1936, 'Effects of the Great Drought on the Prairies of Iowa, Nebraska, and Kansas', Ecology 17, 567-639.

Weaver, J. E. and Albertson, F. W.: 1940, 'Deterioration of Grassland from Stability to Denudation with Decrease in Soil Moisture', Botanical Gazette 101, 598-624.

Weaver, J. E. and Albertson, F. W.: 1956, Grasslands of the Great Plains, Johnsen Publishing Company, Lincoln, NE.

Weaver, J. E., Stoddart, L. A., and Noll, W.: 1935, 'Response of the Prairie to the Great Drought of 1934', Ecology 16, 612-629.

Woodhouse, C. and Overpeck, J. T.: 1999, '2000 Years of Drought Variability in the Central United States', Bull. Amer. Meteorol. Soc. 79, 2693-2714.

Wright, H. E., Almendinger, J. C., and Gruger, J.: 1985, 'Pollen Diagram from the Nebraska Sandhills and the Age of the Dunes', Quatern. Res. 24, 115-120.

Wunder, J. R., Kaye, F. W., and Carstensen, V.: 1999, Americans View their Dust Bowl Experience, University of Colorado Press, Niwot, CO.

(Received 12 December 2000; accepted 19 December 2002) 